\title{
Depósitos sinorogénicos en el antepaís neopaleozoico del cinturón de Famatina, centro-oeste de Argentina: implicancias paleoambientales, paleogeográficas y tectonosedimentarias
}

\author{
Miguel Ezpeleta ${ }^{1}$, Ricardo A. Astini' ${ }^{1}$, Federico Dávila ${ }^{1}$ \\ 'Centro de Investigaciones en Ciencias de la Tierra (CICTERRA)-CONICET, Laboratorio de Análisis de Cuencas, Cátedra de Es- \\ tratigrafía y Geología Histórica, Facultad de Ciencias Exactas, Físicas y Naturales, Universidad Nacional de Córdoba, Av. Vélez \\ Sársfield 1611, $2^{\circ}$ Piso Oficina 7, X5016GCA Córdoba, Argentina. \\ mezpeleta@efn.uncor.edu; raastini@efn.uncor.edu; fmdavila@efn.uncor.edu
}

RESUMEN. En el cinturón de Famatina, ubicado entre las provincias geológicas argentinas de Sierras Pampeanas y Precordillera, se describe y analiza una sucesión de conglomerados de $\sim 400 \mathrm{~m}$, considerada en trabajos previos como la sección superior del intervalo postglacial neopaleozoico del Grupo Paganzo (Pensilvaniano tardío). En este trabajo estos conglomerados (Formación Las Pircas nom.nov.), extensamente desarrollados en Famatina, son separados como una unidad litoestratigráfica diferente asociada a un episodio de deformación, sobre la base de: 1. la presencia de una discordancia angular en su base, 2. un fuerte contraste litofacial con la unidad glacial subyacente y 3. su organización estratigráfica interna. El análisis de facies indica un predominio de depósitos de abanicos aluviales proximales, que pasan en transición hacia sistemas fluviales entrelazados y desarrollo local de depósitos lacustres. La recurrencia de megacapas con bloques y conglomerados de composición granítica indica una significativa exhumación de basamento, sugiriendo actividad tectónica coetánea. Asimismo, los estudios de procedencia indican participación de clastos de areniscas fluviales pensilvanianas y volcanitas ácidas ordovícicas que actualmente se exponen en la sierra de Famatina. Esto es compatible con el análisis de paleocorrientes, que muestra una dispersión de los sedimentos hacia el oeste. La posición de los altos topográficos de basamento al este del arco principal, junto con evidencias de plegamiento, sugieren una etapa de deformación de zócalo dentro del antepaís no descrita con anterioridad. Esto permite explicar la fuente principal de esta cuña clástica depositada de este a oeste parcialmente equivalente a la Formación Tupe en el ámbito de Precordillera. Este modelo de antepaís puede ser comparado con el antepaís fragmentado moderno de los Andes Centrales.

Palabras claves: Cuña conglomerádica, Depósitos sinorogénicos, Antepaís fragmentado, Pensilvaniano tardio-Pérmico Temprano, Centro-oeste de Argentina. 


\begin{abstract}
Synorogenic deposits in the late Paleozoic foreland basin of central-western Argentina: paleoenvironments, paleogeography and tectosedimentary implications. In the Famatina belt, western Argentina, a $\sim 400 \mathrm{~m}$ thick conglomerate succession is extensively developed and has been previously considered as the uppermost section of a postglacial interval (late Pennsylvanian) of the Paganzo Group. Here we separate it as a different lithostratigraphic unit (Las Pircas Formation, nom. nov.) with a significant tectonic meaning based on: 1. the angular discordance at its base; 2. the strong litofacial contrast with the underlying glacial unit and 3. its internal stratigraphic organization. Facies analyses indicate topographically controlled proximal alluvial fans succeeded by braided fluvial systems, and local development of lacustrine deposits. Granite bearing-megaboulder beds and conglomerates indicate significant basement exhumation and tectonic unroofing. Clast composition also depicts early Pennsylvanian sandstones and Ordovician volcanic rocks mainly exposed in the central part of Famatina (at present). Paleocurrent analyses are compatible with a dispersal pattern mostly to the west. The position of basement topographic high further east from the main contemporaneous arc together with evidences of folding allow us to interpret previously unrecognized basement thrusting within the foreland. This may have been the main source for the westward coarse arkosic clastic wedge known in the Argentine Precordillera as the Tupe Formation and equivalents. This late Pennsylvanian-Early Permian foreland model can be compared with the modern broken foreland of the Central Andes.
\end{abstract}

Keywords: Conglomeratic wedge, Synorogenic deposits, Broken foreland, Late Pennsylvanian-Early Permian, Central-western Argentina.

\section{Introducción}

Las cuencas neopaleozoicas del oeste argentino han sido extensamente estudiadas en sus regiones clásicas, tanto desde un punto de vista sedimentológico-estratigráfico como bioestratigráfico (e.g., López Gamundí et al., 1994). Aunque estas cuencas fueron motivo de diversas controversias, explicadas como cuencas extensionales (e.g., Salfity y Gorustovich, 1983) y de 'pull-apart' (e.g., Fernández Seveso y Tankard, 1995), los argumentos estratigráficos (e.g., López Gamundí et al., 1994), estructurales (Dávila et al., 2003) y del magmatismo asociado (e.g., Mpodozis y Kay, 1990) indican el desarrollo de un sistema de antepaís clásico (e.g., Mpodozis y Ramos, 1989; López Gamundí et al., 1989, 1994; Fernández Seveso et al., 1993; Astini, 1996; Ramos, 2000; Ramos y Aleman, 2000). En este sentido, cabe destacar los estudios de López Gamundí et al. (1989) y Fernández Seveso et al. (1993) que abordaron un análisis secuencial, a los efectos de diferenciar etapas de relleno con cierta homogeneidad interna que denominaron megasecuencias. Sin embargo, la existencia de marcados contrastes litofaciales y de espesores en el relleno de las cuencas neopaleozoicas sumado al desarrollo de discordancias localizadas, indica que no debería tratarse como una entidad única subsidiendo regionalmente, sino como depocentros aislados con historias de alzamiento y subsidencia contrastados. Esto resulta una evidente limitación a la hora de establecer megasecuencias regionales en el rango originalmente definido (en el sentido de Sloss, 1963).

Otro problema en la aplicación del modelo secuencial, y para el estudio de las cuencas neopaleozoicas del oeste argentino, es que regiones alejadas de las localidades clásicas están pobremente estudiadas. Algunas, no disponen de mapas actualizados y su estratigrafía está poco comprendida. Un ejemplo de esto lo constituye el cinturón de Famatina, ubicado en la región central de la cuenca de Paganzo (Bodenbender, 1911), donde los afloramientos de Paleozoico superior presentan un gran desarrollo, particularmente en su ladera occidental. En esta región se encuentra el mayor espesor de una sucesión neopaleozoica dominantemente conglomerádica, separada por una discordancia angular de la infrayacente Formación Agua Colorada de edad carbonífera tardía (Limarino, 1987; Gutiérrez, 1995). Esta misma relación discordante, pero con mayor angularidad, se observa sobre la ladera oriental de Famatina, representada por una discordancia reconocida por Parker (1974) y más recientemente descrita por Astini (1998) y Dávila et al. (2003).

Esta sucesión psefítica fue previamente incluida dentro de la porción superior de la Formación Agua Colorada (e.g., Menéndez y González-Amicón, 1979; Gutiérrez, 1995) y se considera este intervalo como parte de un estadio postectónico de relleno del paleorrelieve heredado de la glaciación gondwánica, sin una etapa de deformación asociada (e.g., Limarino, 1987). Sin embargo, la presencia de una clara discordancia angular en la base y los marcados 
contrastes litofaciales y de la estratofábrica entre esta sucesión y las unidades ubicadas por encima y por debajo (Formación Agua Colorada y Formación de la Cuesta respectivamente), permiten definir una nueva unidad formacional, de importancia para el análisis de la cuenca.

Sobre la base de un análisis de facies y de las relaciones estratigráficas de este intervalo estratigráfico, se realiza la definición de la Formación Las Pircas estableciendo su significado paleoambiental. La presencia de esta distintiva unidad conglomerádica junto a su yacencia discordante permite fundamentar la existencia de una etapa de deformación en la región cratónica del antepaís para el intervalo Pensilvaniano Tardío-Pérmico Temprano, marcando la importancia de esta sucesión en el marco de la cuenca de Paganzo.

\section{Marco geológico y estratigráfico}

El área de estudio se encuentra ubicada en la sierra de Famatina, provincia de La Rioja, entre los $28^{\circ}$ y $29^{\circ} \mathrm{S}$ y los $67^{\circ}$ y $68^{\circ} \mathrm{O}$, dentro del antepaís andino en el segmento sur de los Andes Centrales (Fig. 1). Esta región coincide latitudinalmente con lo que Astini (1998) denominó región central de Famatina, que se distingue por la presencia de sedimentitas del Paleozoico temprano, que localmente forman el basamento de las secuencias neopaleozoicas.

La geología de la región (Turner, 1964, 1971) se compone de un basamento cambro-ordovícico constituido por espesas sucesiones marinas con volcanismo asociado (formaciones Negro Peinado, Achavil, Cerro Tocino, Grupo Famatina y Grupo Cerro Morado), intruidos por granitos de edad ordovícica (De Alba, 1979). Estratos continentales carbonífero-pérmicos (Parker, 1974) completan la estratigrafía paleozoica.

Los depósitos neopaleozoicos en la sierra de Famatina, forman parte del Grupo Paganzo (Azcuy y Morelli, 1970; Durand et al., 1996), que fue inicialmente separado en dos formaciones. La Formación Agua Colorada (Turner, 1960), de edad pensilvaniana, constituye la base del grupo y está compuesta por arcosas blanquecinas intercaladas con mantos de carbón, que caracterizan depósitos fluviales postglaciales. Le sucede la Formación de la Cuesta (Turner, 1960), de edad pérmica, conocida en el extremo sur de Famatina como Formación Patquía (De Alba, 1979). Ésta se compone por es-

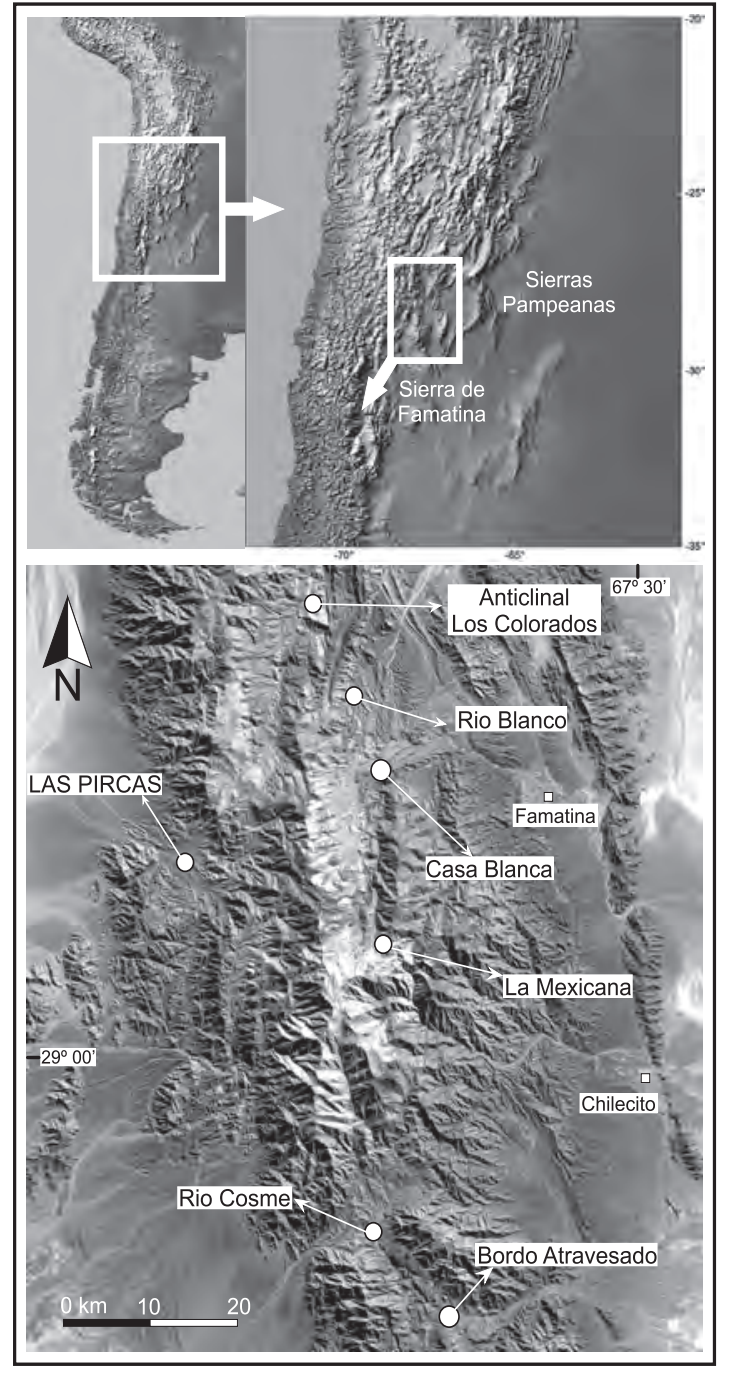

FIG. 1. Ubicación de los principales afloramientos de la Formación Las Pircas en la región central de Famatina.

tratos rojos de origen fluvial, lacustre y eólico (e.g., Limarino y Spalletti, 1986; López y Clerici, 1990). Al Grupo Paganzo le sucede una sección lacustre que Dávila et al. (2005) denominaron Formación La Veteada y correlacionaron, con reservas, con estratos mesozoicos.

Respecto a las relaciones que guardan las unidades que componen el Grupo Paganzo en Famatina central, existe una discrepancia entre aquellos autores que opinan que se disponen en discordancia (e.g., Parker, 1974; Astini, 1998; Dávila et al., 2003) y aquellos que opinan que son concordantes y que dichas discontinuidades se ubican sólo en 
posiciones marginales de la cuenca (e.g., Limarino et al., 1999).

En esta contribución se describe y analiza el significado estratigráfico de un intervalo dentro del Paleozoico tardío denominado Formación Las Pircas, representado por espesos conglomerados de composición dominantemente granítica, limitados por discordancias y que pueden reconocerse con distintas expresiones en todo el ámbito de Famatina, dentro del antepaís andino central.

\section{Formación Las Pircas (nom. nov.)}

La sucesión sedimentaria objeto de estudio está constituida principalmente por conglomerados gruesos y muy gruesos de composición granítica y colores pardos y morados, con algunas intercalaciones de areniscas y pelitas verde-grisáceas, y bancos de carbón. En el ámbito de Famatina su espesor varía entre $\sim 400$ y $50 \mathrm{~m}$. La unidad estudiada registra un salto granulométrico abrupto respecto a las unidades sub- y suprayacentes. Se dispone en discordancia angular sobre las arcosas blancas de la Formación Agua Colorada (Pensilvaniano temprano-medio), aunque localmente yace sobre unidades ordovícicas (Fig. 2) y es cubierta en concordancia por las areniscas rojas de la Formación de la Cuesta (Pérmico Temprano-medio). Se propone el nombre de Formación Las Pircas para este intervalo, en alusión al nombre de la quebrada en la que se encuentra su estratotipo (285'23”S-6757'23”'O, Fig. 1).

\subsection{Ladera occidental de Famatina}

En su estratotipo, la Formación Las Pircas presenta un espesor máximo de $\sim 400 \mathrm{~m}$ y yace sobre la Formación Agua Colorada en suave discordancia angular $\left(\sim 5^{\circ}\right)$. Localmente, solapa al Granito $\tilde{\mathrm{Nu}}-$ ñorco de edad ordovícica (Fig. 2a), afectado por una intensa deformación frágil (cataclasita). La sucesión posee un arreglo general granodecreciente y comienza con conglomerados muy gruesos que constituyen la facies predominante en esta sección. Suelen intercalar facies psamíticas, en niveles que no superan los $20 \mathrm{~m}$. Recurrentemente se encuentran intercalados bancos carbonosos de espesores que varían entre 2 y $0,1 \mathrm{~m}$. En la quebrada del río Cosme (Fig. 1), $40 \mathrm{~km}$ al sur del estratotipo, la Formación Las Pircas tiene un espesor de $\sim 120 \mathrm{~m}$ y se apoya en no concordancia sobre el basamento granítico ordovícico. En dicha localidad está sobre-
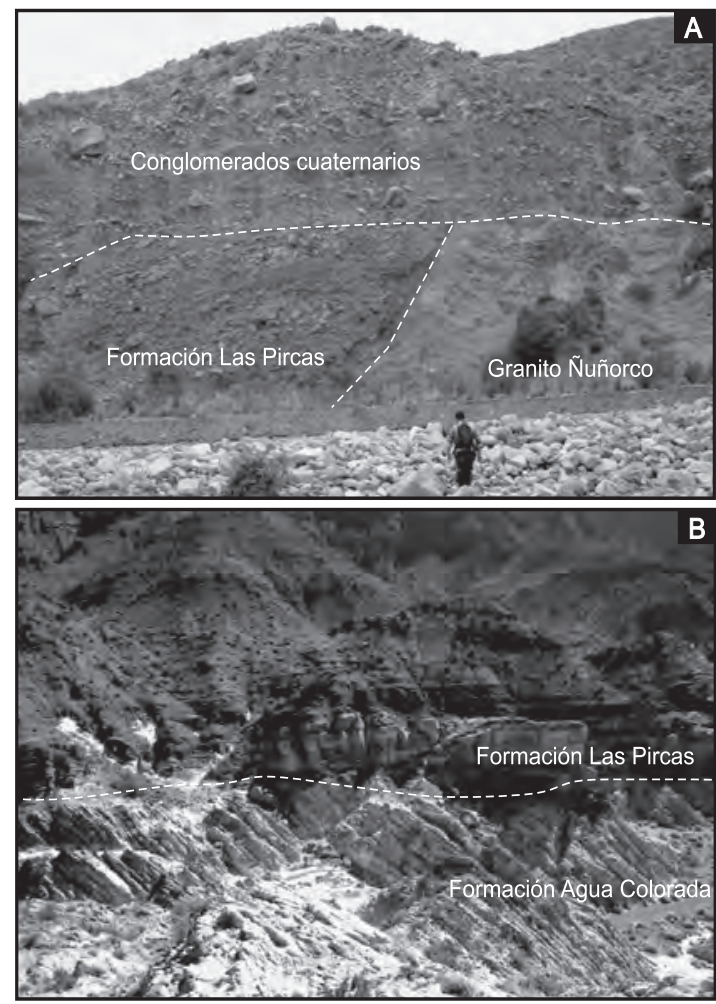

FIG. 2. Relaciones estratigráficas de la Formación Las Pircas. A. No concordancia sobre granitos ordovícicos cataclásticos (Granito Ñunorco). Depósitos aluviales cuaternarios cubren la unidad; B. Discordancia angular $\left(\sim 40^{\circ}\right)$ sobre los depósitos fluviales de la Formación Agua Colorada (Pensilvaniano temprano). Anticlinal Los Colorados.

puesta en forma concordante por la Formación de la Cuesta. Tiene un arreglo general granodecreciente y pueden reconocerse ciclos menores de 30-40 m con la misma tendencia granulométrica. En el puesto Bordo Atravesado, ubicado $10 \mathrm{~km}$ al SE del río Cosme (Fig. 1), la Formación Las Pircas tiene un espesor de $50 \mathrm{~m}$ y se sobrepone a volcanitas ordovícicas del Grupo Cerro Morado, en una sucesión netamente conglomerádica de color morado y blanquecino, donde se intercalan numerosos bancos de carbón. Se destaca un nivel a $18 \mathrm{~m}$ de la base que presenta clastos aislados de composición granítica de hasta $5 \mathrm{~m}$ de lado. Es importante destacar que en esta región la unidad es cubierta por la Formación de la Cuesta en discordancia angular de alto ángulo $\left(40^{\circ}\right)$. En Valle Hermoso (70 km al norte de Las Pircas, Fig. 1), no se reconocieron las típicas facies conglomerádicas gruesas de la unidad. Un intervalo de $350 \mathrm{~m}$ de espesor, dominantemente arcósico con 
colores morados y blanquecinos junto a abundantes bancos de carbón, se dispone entre las formaciones Agua Colorada y de la Cuesta. Este intervalo representaría un equivalente lateral de las facies típicas de la Formación Las Pircas.

\subsection{Ladera oriental de Famatina}

En el núcleo del anticlinal Los Colorados (Fig. 1), se reconocieron conglomerados gruesos en discordancia angular sobre la Formación Agua Colorada, litológica y estratigráficamente semejantes a los definidos en la ladera occidental de Famatina. Si bien una discordancia angular fue reconocida en el Paleozoico tardío de esta región (Parker, 1974; Astini, 1998; Dávila et al., 2003) la misma separa las formaciones Agua Colorada y Las Pircas (Fig. 2b). En esta localidad, los conglomerados morados de la Formación Las Pircas contienen numerosas intercalaciones de bancos de carbón de hasta $2 \mathrm{~m}$ de espesor que contrastan en granulometría y coloración, con las areniscas rojas de la Formación de la Cuesta que se sobreponen en concordancia. El espesor de la Formación Las Pircas en este perfil es de $130 \mathrm{~m}$, con un arreglo general tripartito donde se destaca un intervalo de areniscas finas y pelitas entre cuerpos psefíticos en la base y el tope respectivamente. En las cabeceras del río Blanco (Fig.1), $5 \mathrm{~km}$ al sur del núcleo del anticlinal Los Colorados, la Formación Las Pircas también se apoya en discordancia angular $\left(18^{\circ}\right)$ sobre la Formación Agua Colorada. En esta región la Formación Las Pircas constituye una sucesión de $80 \mathrm{~m}$ de espesor con un arreglo granodecreciente, siendo la base dominada por niveles de conglomerados tabulares amalgamados de $>2 \mathrm{~m}$ de espesor, intercalados con cuñas de areniscas gruesas y microconglomerádicas. Hacia el techo hay un aumento en la proporción de areniscas, de niveles limoarcilíticos y de silcreta. En el puesto Casa Blanca (Fig.1), 6 km al SE del río Blanco, sobre el río Achavil, la discordancia entre las formaciones Agua Colorada y Las Pircas es de bajo ángulo $\left(\sim 5^{\circ}\right)$. En esta localidad, la Formación Las Pircas tiene un espesor de $110 \mathrm{~m}$ y un arreglo general granodecreciente, marcado por el pasaje de los conglomerados basales a areniscas gruesas lenticulares seguido de un intervalo limoarcilloso en el tope. En la mina La Mexicana, la Formación Las Pircas se apoya en discordancia angular sobre metasedimentitas cámbricas de la Formación Achavil (Collo, 2006). Está formada por una sucesión de $150 \mathrm{~m}$ de conglomerados gruesos, muy mal seleccionados y macizos, a los que se intercalan cuñas o lentes de areniscas gruesas especialmente en la base del perfil. En estas últimas dos localidades, la Formación de la Cuesta suprayace en forma concordante.

\section{Análisis de facies}

En la Formación Las Pircas se reconocieron ocho facies principales, que se describen a continuación: 1. conglomerados de bloques clastosoportados, 2. conglomerados gruesos matriz soportados, 3. conglomerados medianos lenticulares clastosoportados, 4. paleorregolitos, 5. conglomerados de grano fino lenticulares, $\mathbf{6}$. areniscas sabulíticas tabulares localmente bioturbadas, 7. areniscas finas a medias y limolitas verdes y 8. mantos de carbón y areniscas con matriz carbonosa. Las facies son comparadas con el código litofacial de Miall (1996) con el objetivo de estandarizar su clasificación.

\subsection{Conglomerados de bloques clastosoporta- dos (Gcm)}

Se trata de conglomerados gruesos y muy gruesos de color pardo rojizo, con una fábrica clastosoportada y abierta, muy mal seleccionados (Fig. $3 \mathrm{a})$. Se disponen en cuerpos tabulares o lenticulares expandidos lateralmente hasta $200 \mathrm{~m}$ y $4-5 \mathrm{~m}$ de espesor, con contactos irregulares y generalmente difusos (estratificación cruda). Los bloques presentan una marcada homogeneidad composicional granítica. La fábrica es dominantemente caótica, donde la matriz es muy escasa y está formada por areniscas gruesas y conglomerados de grano fino. Poseen muy mala selección incluyendo bloques sobredimensionados de más de $10 \mathrm{~m}$ (eje a) que se disponen en forma errática o formando agrupamientos (Fig. 3b). Los bloques de mayor tamaño son subredondeados mientras que la población dominante, formada por guijas y guijarros, presenta un mayor redondeamiento.

Interpretación. La homogeneidad interna de los cuerpos psefíticos, la mala selección interna, los tamaños sobredimensionados de bloques sugieren que se trata de depósitos de flujos gravitacionales, con transporte limitado (cf. Nemec y Steel, 1984). Rasgos similares son interpretados como episodios discretos en depósitos de avalanchas actuales en 


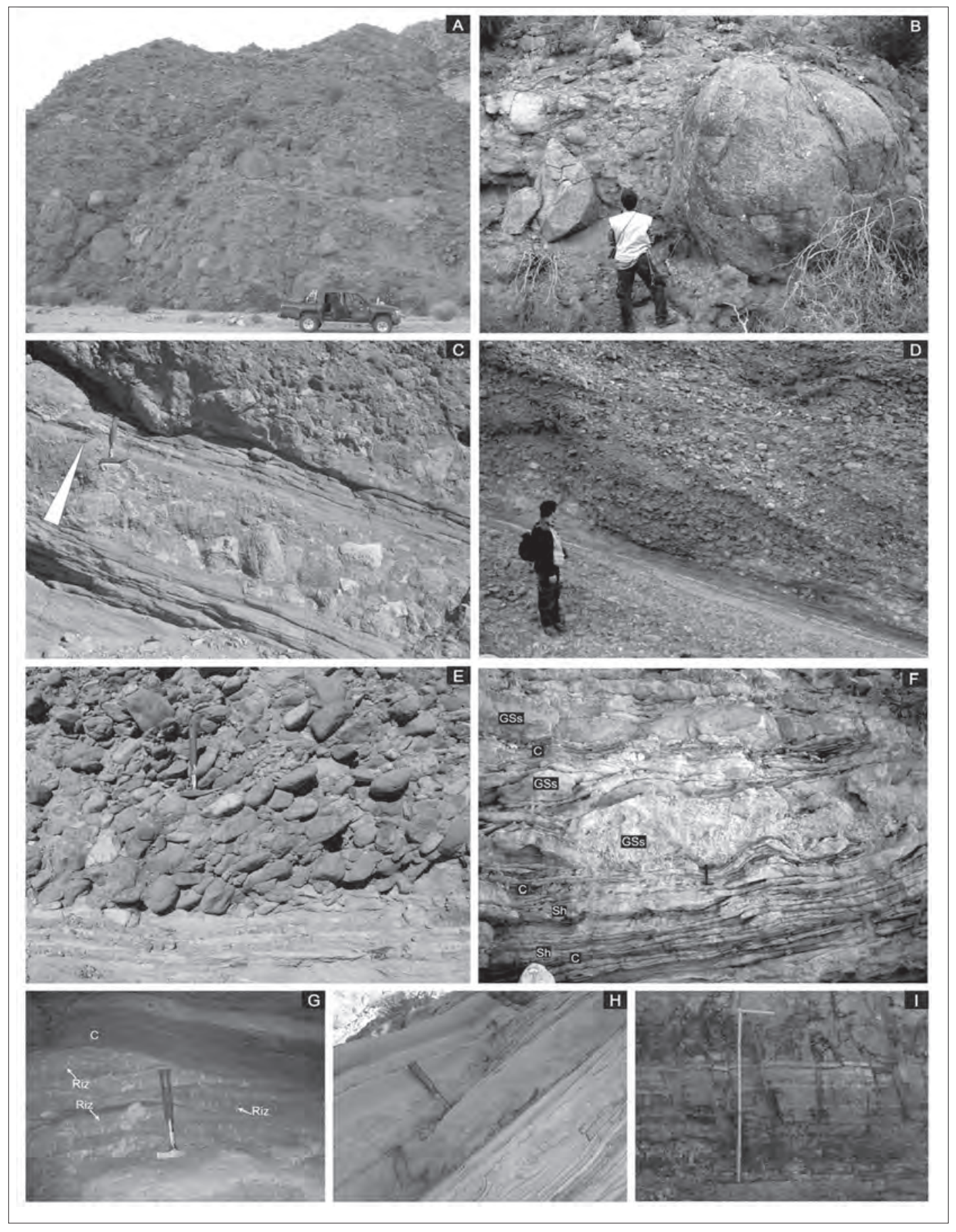

FIG. 3. Facies de la Formación Las Pircas: A. Facies de conglomerados de bloques clastosoportados; B. Clastos sobredimensionados $>2 \mathrm{~m}$ dispuestos en forma errática dentro de la facies de conglomerados de bloques clastosoportados; C. Facies de flujos de detritos con gradación normal; D. Facies de conglomerados medianos lenticulares clastosoportados con estratificación cruzada de bajo ángulo de frentes de barras gravosas; E. Imbricación de clastos en la facies de conglomerados medianos lenticulares clastosoportados; F. Conglomerados de grano fino lenticulares intercalados con finas capas de carbón (C); G. Los rizohalos (Riz) en la facies Sh indican el desarrollo de paleosuelos incipientes; H. Facies de areniscas gradadas y limolitas verdes con laminación convoluta; I. Mantos tabulares de carbón. 
sistemas coluviales ('rockfalls', cf. Blikra y Nemec, 1998). La desestabilización de estos materiales comúnmente es asociada a episodios de sismicidad activa (e.g., Norris, 1994). La fábrica abierta bien preservada y la presencia de matriz arenosa, estaría asociada a una etapa de infiltración posterior a la depositación o a un control de la fuente dominantemente granítica que no proporciona suficientes finos.

\subsection{Conglomerados gruesos matriz soportados (Gmm)}

Se trata de conglomerados gruesos pobremente estratificados con una fábrica matriz soportada, mal seleccionados, internamente desorganizados o macizos. Los bancos conglomerádicos son tabulares y menores a $1 \mathrm{~m}$ de espesor, con contactos planos y difusos. El tamaño promedio de los clastos varía entre 2 y $25 \mathrm{~cm}$, conteniendo bloques sobredimensionados $>1 \mathrm{~m}$. La matriz es de color rojo-morado y se compone de una mezcla textural entre arcillas, limos y arenas gruesas. Generalmente los bancos no presentan estructuras sedimentarias internas, salvo gradación normal (Fig. 3c). Algunos bancos poseen sutil gradación inversa en su intervalo basal y bloques protruyendo desde el tope con ejes en posición subvertical.
Interpretación. Estos depósitos psefíticos matriz soportados, desorganizados y carentes de estructuración interna pueden interpretarse como depósitos de flujos de detritos generados por flujos viscosos y con baja movilidad. Las relaciones entre espesores (capacidad) y tamaños máximos (competencia) son consistentes con depósitos de flujos de detritos cohesivos (Nemec y Steel, 1984; Schultz, 1984) (Fig 4).

Las variaciones en el arreglo interno de esta facies pueden interpretarse por efectos de mayor o menor dilución del flujo. Los cuerpos que muestran gradación inversa pueden interpretarse como flujos afectados en su parte inferior por esfuerzos de cizalle mayor que la parte superior que se comportó como un tapón rígido (Nemec y Postma, 1993). En cambio, las capas con gradación normal y bases erosivas representan flujos más diluidos y desarrollo de turbulencia (Lawson, 1982). Los bloques flotantes indican una alta fuerza estática del flujo ('matrix strength', Hiscott y James, 1984), comunes en flujos con alta viscosidad y dinámica sublaminar (Hampton, 1979). La formación de estos flujos de detritos indica fuertes pendientes y una importante disponibilidad de material no consolidado, movilizado repentinamente a partir de lluvias intensas que actúan como desencadenantes.

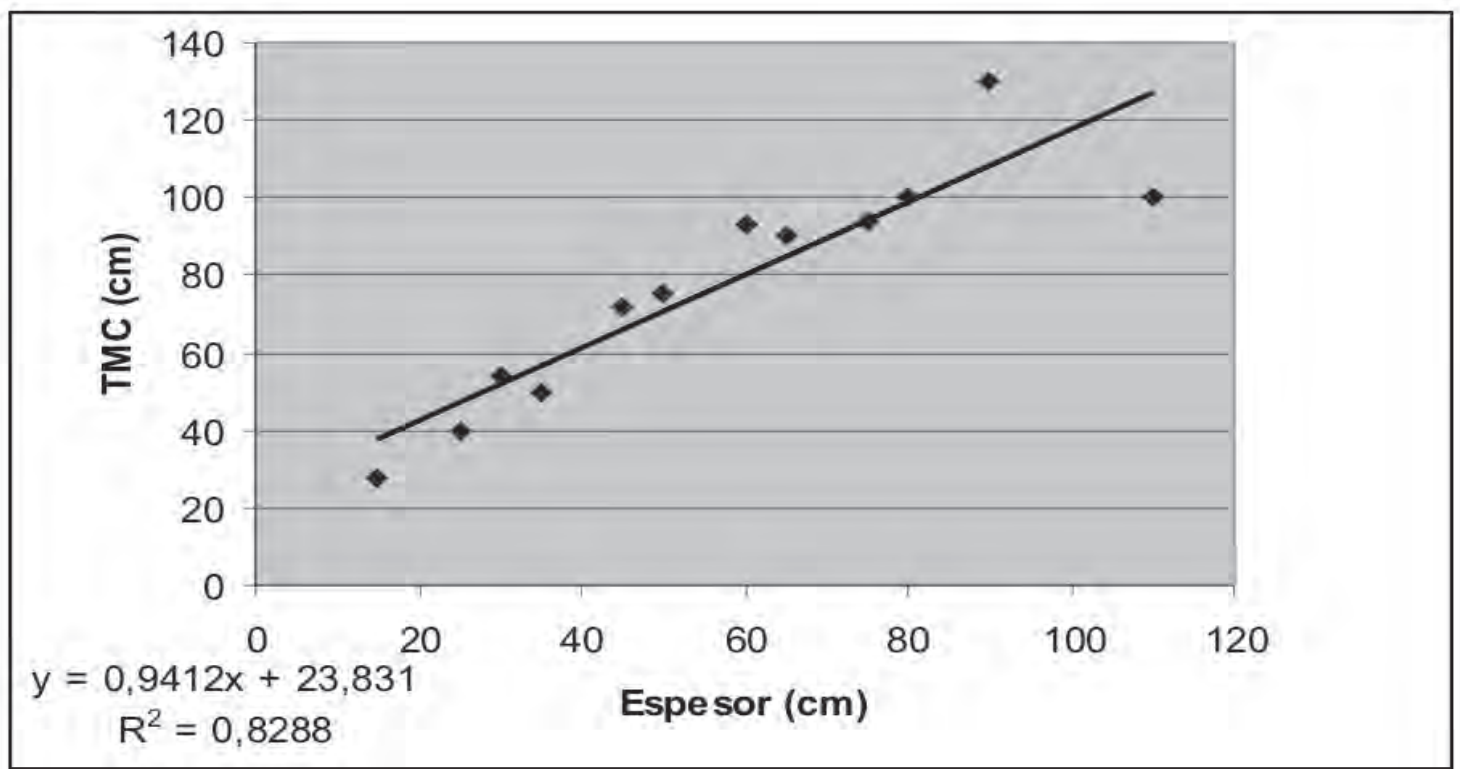

FIG. 4. Relaciones entre los espesores de capas individuales versus tamaños máximos de dichas capas para la facies de conglomerados gruesos matriz soportados. 


\subsection{Conglomerados medianos lenticulares clastosoportados (Get)}

Se trata de conglomerados medianos a gruesos, lenticulares, clastosoportados y de color morado, que se diferencian de la facies anterior por presentar mejor arreglo interno, mejor selección, y menor granulometría. Se presentan en cuerpos lenticulares amalgamados, con extensiones laterales que superan los $30 \mathrm{~m}$ y espesores máximos de $3 \mathrm{~m}$. Sus bases son cóncavas, irregulares y es común encontrar estructuras de corte y relleno. Los techos de estos conglomerados son planos o convexos. Poseen una selección regular a pobre, con tamaño máximo promedio entre 20 y $30 \mathrm{~cm}$. Los clastos son redondeados a subredondeados. La matriz está formada por arena gruesa a sabulítica y constituye menos del $20 \%$ del total de la roca. Localmente, la facies incluye clastos sobredimensionados de $2 \mathrm{~m}$ en la base de estos bancos. En la estratofábrica predomina la estratificación cruda, artesas difusas y estratificación cruzada de alto ángulo(Fig. 3d). En numerosos bancos se observaron agrupamientos de clastos con fábrica abierta con el eje $b$ imbricado y transversal al flujo a(t)-b(i) (Fig. $3 \mathrm{e})$. Localmente, hay bancos con gradación normal, donde la fracción psamítica alcanza valores superiores $(\sim 40 \%)$.

Interpretación. El ordenamiento clastosoportado y los contactos basales erosivos de estos cuerpos lenticulares indican la presencia de flujos fluidales y turbulentos altamente erosivos. Asimismo, las fábricas imbricadas, las matrices arenosas, y el marcado redondeamiento de clastos con agrupamientos se atribuyen a mecanismos más diluidos, turbulentos y selectivos que la facies precedente, producto de procesos de escorrentía fluvial. La clastometría sugiere que esta facies corresponde a depósitos relativamente proximales en relación al área fuente, compatible con depósitos propios de cursos entrelazados gravosos (cf. Nemec y Postma, 1993). La presencia de conglomerados gruesos clastosoportados con bases cóncavas y techo plano, junto al desarrollo de estratificación cruzada, es indicativa de la formación de barras como relleno de canales (cf. Lunt et al., 2004). En la base de estos canales se observan agrupamientos de clastos con fábrica abierta que representan la sedimentación de carga de fondo y evidenciarían una etapa inicial de mayor competencia del flujo luego de un pico máximo de turbulencia. La matriz arenosa probablemente es producto del entrampamiento de sedimentos por infiltración (cf. Frostick et al., 1984) propia de períodos con régimen menguante. Esto indicaría una estacionalidad climática.

\subsection{Paleorregolitos}

Se trata de depósitos mal seleccionados y matriz arcósica inmadura, con un rango de tamaños máximos entre $10 \mathrm{~cm}$ y $30 \mathrm{~cm}$, que se apoyan directamente sobre el basamento granítico que en su tope posee una notable capa de alteración. Los contactos basales de esta facies respecto al granito infrayacente son difíciles de discernir dado el pobre contraste textural y la aparente gradación entre la roca granítica alterada y el depósito suprayacente. El espesor de esta facies es variable, pudiendo alcanzar un máximo de $3 \mathrm{~m}$. Los clastos mayores, intensamente alterados, presentan un relativo redondeamiento. La matriz está formada por granos de tamaño arena gruesa y muy gruesa y microscópicamente se observan tanto feldespatos como micas abundantes. En menor medida la matriz contiene arcilla y limo intersticial. La matriz alcanza el 20\% de la roca. Internamente esta facies presenta una estructura caótica y no se reconocieron estructuras mecánicas, ni ordenamiento interno.

Interpretación. El pasaje transicional al sustrato granítico inalterado, sumado a la pobre selección del depósito y la ausencia de texturas y fábricas mecánicas sugiere que se trataría de una capa de alteración superficial desarrollada directamente sobre el basamento granítico. La presencia de clastos del granito alterado se interpreta como evidencia de un escaso transporte. El buen redondeamiento de los fragmentos de mayor tamaño se atribuye a procesos de meteorización esferoidal por analogía con los 'corestones' descritos por Ollier y Pain (1996). Posiblemente, parte de la matriz psamo-pelítica del depósito sea también producto de degradación química y alteración in situ del basamento granítico o producto de iluviación e infiltración posterior. Por su composición similar al sustrato granítico y su yacencia, esta facies podría indicar el desarrollo de mantos regolíticos localizados con escaso o nulo transporte (Ollier y Pain, 1996). Los espesores variables que se registran pueden estar evidenciando la existencia de una paleosuperficie afectada por meteorización desarrollada sobre el basamento granítico de la región, que permitió la acumulación 
local de estos mantos regolíticos, sugiriendo episodios con estabilidad del relieve.

\subsection{Conglomerados de grano fino y areniscas guijosas lenticulares (GSs)}

Se trata de conglomerados de grano fino rosados dispuestos en bancos lenticulares normalmente amalgamados, con estratificación cruda. Se presentan en bancos lenticulares expandidos con extensiones laterales menores a $20 \mathrm{~m}$ y espesores por debajo del metro. Sus bases son netas, onduladas e irregulares y los rellenos gradados y gradado-estratificados con una mayor proporción de clastos en la base (Fig. 3f). El tamaño máximo de clastos es de $8 \mathrm{~cm}$ y es común encontrar imbricación de clastos. Localmente, poseen estratificación paralela y cruzada. Entre la estratificación cruzada dominan la de tipo planar y la de bajo ángulo. Se reconocen, además, superficies diagonales asintóticas de mayor escala (sigmoides), laminación flaser y lenticular.

Interpretación. Tanto las geometrías descritas como la secuencia de rellenos gradados y la ciclicidad del depósito indican rellenos de canales fluviales que recurrentemente comienzan con una fase erosiva y gradualmente decrecen en su intensidad de transporte. Las capas lenticulares de mayor espesor indican una mayor incisión local y menor movilidad lateral. Los bancos con estratificación cruzada planar y de bajo ángulo son interpretados como resultado de macroformas con desarrollo de caras de avalancha en sentido del flujo (barras transversales).

\subsection{Areniscas sabulíticas tabulares localmente bioturbadas (Sh)}

Se trata de areniscas gruesas a sabulíticas tabulares de color rosa, dispuestas en capas delgadas que localmente están amalgamadas (Fig. 3g). Poseen espesores variables menores a $70 \mathrm{~cm}$ y su continuidad lateral es normalmente superior a $100 \mathrm{~m}$. Estos bancos poseen una marcada recurrencia con contactos netos y planos. Internamente desarrollan estructura maciza o gradada y ocasionalmente se observa estratificación y laminación paralela difusa y cruzada. Localmente, la facies rellena topografías canalizadas (de hasta $50 \mathrm{~cm}$ de profundidad) y posee agrupamientos localizados de clastos imbricados en su base. El tamaño máximo de los clastos es de
$5 \mathrm{~cm}$. Se observan estratos rojizos con espesores menores a $50 \mathrm{~cm}$ que poseen estructuras tubulares con disposición subvertical y formas irregulares, reemplazadas por calcita y sílice, que alcanzan hasta $8 \mathrm{~cm}$ de longitud y $\sim 1 \mathrm{~cm}$ de diámetro (Fig. 3f).

Interpretación. La disposición tabular de los bancos psamíticos y la escasez de estructuras tractivas, favorecen la interpretación de depósitos a partir de flujos tractivos con pobre canalización y una marcada agradación, evidenciada por la superposición de estos bancos. Las capas de geometría planar y laminación paralela pueden ser interpretadas como mantos de crecida en la terminación de abanicos y en llanuras de inundación de sistemas fluviales (Olsen, 1989). Los agrupamientos de clastos sustentan localmente la existencia de flujos más turbulentos durante etapas con carga de lecho activo. Estos son interpretados como capas residuales ('lags'). Los tubos subverticales, por su parte, son interpretados como rizolitos y rizohalos producto de pedogénesis (cf. Kraus y Hasiotis, 2006). Estos caracterizarían a regiones con escasa tasa de sedimentación y una estacionalidad climática que habría permitido el desarrollo de paleosuelos. La coloración rojiza de estos horizontes indica la presencia de hematita, que junto a los rizolitos y rizohalos carbonáticos implican condiciones de moderado a buen drenaje dentro de un ambiente oxidante (Schwertmann, 1993). La ausencia de horizontación y de materiales parentales pobremente seleccionados lleva a comparar estos depósitos con los paleosuelos inmaduros formados durante el estadio 1 de Kraus (1999).

\subsection{Areniscas finas a medias y limolitas verdes (SFI)}

Se trata de una alternancia rítmica de hasta $30 \mathrm{~m}$ de espesor de areniscas finas a medias desarrolladas en capas tabulares, con limoarenitas y pelitas limosas verde grisáceas. La relación arenisca-pelita es relativamente alta $(>5: 1)$, mostrando tendencias tanto estratocrecientes como decrecientes. Las areniscas no superan los $20 \mathrm{~cm}$ de espesor, y poseen contactos netos y planos. Localmente, presentan estructuras de carga y flujo (turboglifos) en la base. Son gradadas o desarrollan laminación paralela, y es común encontrar laminación convoluta y estructuras flamígeras (Fig. 3h). Ocasionalmente, presentan 
laminación cruzada y óndulas de oleaje en la parte superior de capas arenosas. Las capas pelíticas aparecen coronando las capas arenosas en finas láminas menores a $5 \mathrm{~cm}$, o en bancos de hasta $5 \mathrm{~m}$ de espesor, que desarrollan laminación entre 1-2 cm.

Interpretación. La presencia de capas de areniscas gradadas con base erosiva y frecuentes estructuras de carga es indicativa de depósitos formados a partir de flujos turbidíticos en ambientes lacustres. Las estructuras sedimentarias internas reflejan, a su vez, una disminución progresiva de la velocidad de estas corrientes que habrían culminado con depósitos pelíticos. La laminación convoluta es también un rasgo común en depósitos turbidíticos caracterizados por una alta tasa de descarga. Las pelitas verdes que aparecen coronando las capas arenosas indican decantación residual en cuerpos de agua relativamente perennes. Las marcas de oleaje en el tope de algunos niveles reflejan una limitada profundidad de estos cuerpos de agua, donde la base del oleaje habría afectado el fondo. La presencia de intervalos pelíticos con escasas intercalaciones de areniscas indicaría, por el contrario, etapas de expansión lacustre.

\subsection{Mantos de carbón y areniscas con matriz carbonosa (C)}

Se trata de horizontes carbonosos de color negro que presentan proporciones variables de material detrítico, compuesto de arenas finas a gruesas inmersas en la matriz carbonosa. El horizonte más importante de $\sim 1,5 \mathrm{~m}$ de espesor, ha sido explotado a través de labores mineras (Mina Las Pircas; Menéndez y González-Amicón, 1979). Localmente aparecen niveles de conglomerados de grano fino clastosoportados, donde la participación de material carbonoso en la matriz arenosa es menor al $10 \%$. Aunque predominan las geometrías tabulares, se observaron cuerpos lenticulares explayados (relación extensión lateral/espesores <30). Los espesores de los horizontes varían entre 2 y $15 \mathrm{~cm}$ para los bancos con participación clástica mayor (Fig. 3f), y entre $10 \mathrm{~cm}$ y $1 \mathrm{~m}$ para los niveles con una escasa fracción detrítica (Fig. 3g, i). Sus contactos son netos y planos, aunque localmente presentan bases cóncavas.

Interpretación. Los mantos tabulares de carbón de mayor espesor y sin participación clástica, indican la acumulación de abundante materia orgánica leñosa por decantación en condiciones de pobre drenaje. Estos depósitos, que carecen de evidencias de retrabajo por parte de corrientes tractivas, comúnmente son asociados a llanuras de inundación anegadas y sistemas palustres (e.g., Boardman, 1989). Por otra parte, los bancos con profusa participación de material clástico arenoso, con bases cóncavas y estructuras internas tractivas, estarían asociados a erosión y retrabajo del material carbonoso primario e incorporación de material detrítico. Los bancos lenticulares y con participación clástica más gruesa podrían relacionarse con mantos de crecida más importantes o bien con depósitos de canal. Las proporciones variables de material clástico y las diferentes estructuras internas, sugieren la coexistencia de mantos de carbón autóctono sin evidencias de retrabajo junto a material carbonoso alóctono que es incorporado en la matriz como carbón detrítico dentro de depósitos que evidencian un origen tractivo (cf. Oesterlen y Lepper, 2005).

\section{Asociaciones de facies}

De acuerdo con el ordenamiento vertical de las facies descritas y de su interrelación pueden describirse cuatro asociaciones paleoambientalmente significativas. La figura 5 muestra la columna tipo de la Formación Las Pircas.

\subsection{Asociación de conglomerados desorgani- zados}

Es la asociación de facies más representativa de la Formación Las Pircas, y está formada dominantemente por facies gruesas con muy mala selección ( $\sim 90 \% \mathrm{Gcm}$ y $\mathrm{Gmm})$, donde los espesores de sus capas y las texturas indican flujos de gravedad, y fuentes localizadas y proximales (Fig. 5a). Ocasionalmente alternan facies conglomerádicas y psamíticas mejor organizadas (Gct y GSs) a manera de cuñas. La predominancia de facies psefíticas gruesas y mal estructuradas con intercalaciones de abundantes megacapas con bloques, la ausencia de depósitos finos, los tamaños máximos promedios y la frecuencia de clastos sobredimensionados indican zonas proximales de abanicos aluviales con un área de captura pequeña y laderas primarias de alto gradiente (Nemec y Steel, 1984). Esta asociación de facies es también común en rellenos de trinchera en la parte interna de un 


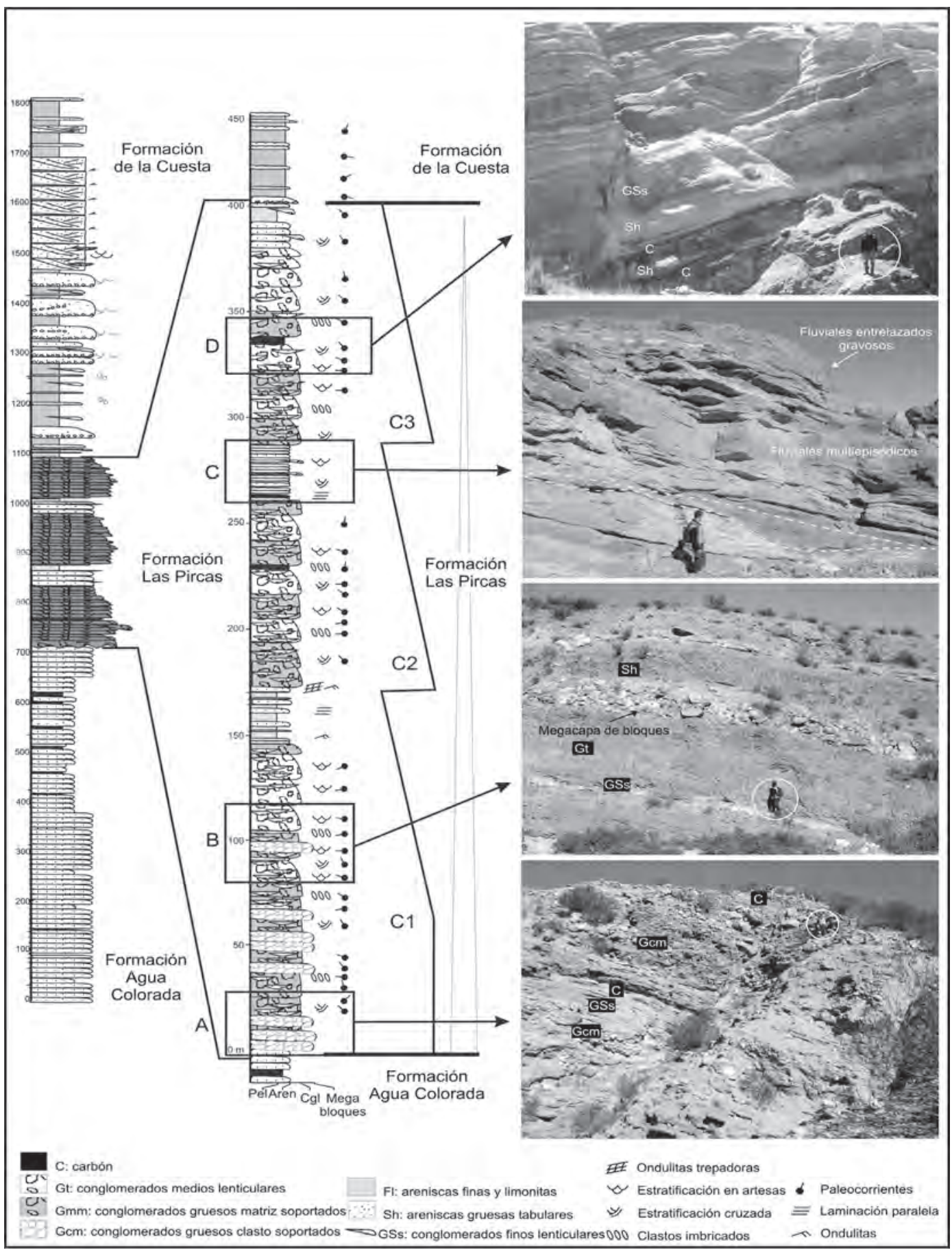

FIG. 5. Columna estratigráfica general de la cuenca de Paganzo (izquierda) y del estratotipo de la Formación Las Pircas (derecha). Facies y asociaciones de facies constituyentes de la unidad se ubican en la sección (los círculos señalan escala). Nótese cómo los depósitos gravitacionales prevalecen en la porción inferior de la sección marcando una tendencia general granodecreciente. C1, C2 y C3 indican diferentes megaciclos. A. Asociación de facies de conglomerados desorganizados; B. Asociación de facies de conglomerados organizados con megacapas de bloques aislados; C. Asociación de areniscas y conglomerados fluviales multiepisódicos con incisiones de canales, sobrepuestos por depósitos fluviales gravosos de la base de C3; D. Intercalaciones de mantos carbonosos (C) dentro de los depósitos fluviales entrelazados. 
abanico (cf. DeCelles et al., 1991), vinculados con relieve joven y con cuencas imbríferas pequeñas (Blair y McPherson, 1994). Esta asociación indica un predominio de flujos gravitacionales, donde las sedimentitas fueron transportadas por corrientes y flujos en masa incluidos genéricamente como procesos de baja eficacia de transporte (Colombo, 1992), típicos de regiones apicales de abanicos con pendientes de entre $12,9^{\circ}$ y $9,1^{\circ}$ (cf. Blair y McPherson, 1994) o eventualmente propios de depósitos coluviales.

Cabe destacar que la mejor exposición de esta asociación se presenta en el valle de Las Pircas. No obstante, la misma se ha encontrado rellenando paleovalles encajados desarrollados sobre el basamento granítico, que por su disposición casi ortogonal se interpretan como afluentes del valle principal. Las sedimentitas que rellenan estos paleovalles poseen una organización interna caótica y tamaños de bloques de más de $6 \mathrm{~m}$ indicando depósitos de caída, asociados a laderas con alto gradiente y muy próximos al área fuente, depositados por encima del ápice del abanico. Estos depósitos comúnmente no se conservan debido a las altas tasas de retrabajo que modifican esta sección del abanico. Sin embargo, su preservación se habría incrementado en los paleovalles transversales que se habrían mantenido como formas remanentes (valles colgantes) de la glaciación gondwánica.

\subsection{Asociación de conglomerados organizados}

Se diferencia de la asociación de facies anterior por presentar una menor granulometría promedio, mayor redondeamiento general de clastos, y mejor organización y estructuración interna (artesas difusas, estratificación diagonal y cuñas de arena). $\mathrm{Su}$ exposición más importante se encuentra en la quebrada Las Pircas, estratotipo de la unidad. Esta asociación de facies se compone principalmente de conglomerados medios clastosoportados (Gct, $\sim 60 \%$ ) y cuñas de areniscas gruesas y conglomerados de grano fino lenticulares (Sh y GSs, $25 \%$ ), y localmente conglomerados gruesos matriz soportados (Gmm, 10\%), y mantos carbonosos (C, $5 \%$ ) (Fig. 5b, c). La presencia de lentes conglomerádicos con base erosiva y estratificación cruzada es característica de ríos entrelazados gravosos (cf. Bridge, 2003) y marca un claro contraste con los depósitos psamíticos de la llanura de inundación (Fig. 3d, ver más adelante). Los pocos lentes arenosos son similares a los que rellenan paleocanales menores inactivos y sectores deprimidos en abanicos actuales. Los escasos flujos de detritos se interpretan como derivados de superficies inestables dentro del propio sistema aluvial, que produce retrabajo de estos materiales. La preponderancia de facies con predominio de estructuras tractivas, la matriz dominantemente arenosa, y la ausencia de facies fangosoportadas, permite pensar en un dominio de agentes fluidales como procesos de transporte, depositación consistente con mecanismos de alta eficiencia (Colombo, 1992). Esta asociación de facies es atribuida a dilución y encauzamiento, procesos característicos de las partes medias a distales de un sistema aluvial. Esto, a su vez, sugiere una ampliación del área de captura, que genera un incremento en los volúmenes de agua, turbulencia y flujos más erosivos (Blair, 1987).

\subsection{Asociación de pelitas y areniscas tabulares gradadas}

Se compone de pelitas y areniscas finas ( $\mathrm{Fl}$, $\sim 75 \%$ ), con participación menor de mantos de areniscas sabulíticas (Sh, $\sim 10 \%$ ), conglomerados de grano fino lenticulares (GSs, $10 \%$ ) y horizontes carbonosos $(\mathrm{C}, \sim 5 \%)$. Los afloramientos con mejor exposición se encuentran en la quebrada Las Pircas, y en el núcleo del anticlinal Los Colorados sobre la ladera oriental de Famatina.

Esta asociación de facies sugiere el desarrollo de episodios lacustres. La coloración verde-grisácea de los niveles más finos indicaría la existencia de un cuerpo de agua lo suficientemente profundo y perenne donde se habrían depositado turbiditas lacustres. Los depósitos turbidíticos caracterizados por el desarrollo de secuencias de flujo menguante con importante tasa de agradación vertical (trenes de 'ripples' trepadores) se relacionarían con flujos hiperpícnicos vinculados con una etapa de mayor profundidad relativa. La aparición de trenes de ondulitas de oleaje y bancos carbonosos parcialmente redepositados en el tope de los depósitos lacustres, indica somerización progresiva y alternancia de momentos de tracción por oleaje y decantación, que en ocasiones genera estratofábricas heterolíticas. Generalmente, hacia el tope de esta asociación de facies se observa una disminución progresiva de la relación arenisca/pelita y un pasaje relativamente 
abrupto a facies psamíticas y conglomerados de grano fino, indicando una etapa de colmatación del lago y una rápida reactivación de sistemas fluviales $\mathrm{y}$ aluviales. No se registraron paquetes con estratificación cruzada de grandes portes indicativos de frente deltaico.

\subsection{Asociación de areniscas y conglomerados multiepisódicos}

Esta asociación de facies está formada por areniscas sabulíticas tabulares y conglomerados de grano fino lenticulares (Sh y GSs, $70 \%$ ), con recurrente participación de conglomerados lenticulares medianos (Gct, $20 \%$ ) y bancos de carbón (C, $\sim 10 \%$ ) (Figs. 3f y 5c, d). La mejor exposición de esta asociación de facies se encuentra en Valle Hermoso.

Los espesores de bancos y las granulometrías promedio son compatibles con ríos entrelazados con carga mixta areno-gravosa con caudal perenne. La escasa proporción de finos preservada y frecuente amalgamación entre capas indica gran movilidad de los cauces con relación a la tasa de hundimiento (cf. Slingerland y Smith, 2004). Dicha movilidad puede relacionarse con mecanismos autocíclicos vinculados con variaciones estacionales de la descarga y/o a procesos de avulsión, propios de un sistema fluvial entrelazado (Bridge, 2003; Ashworth et al., 2007). La presencia de mantos de carbón delgados y paleosuelos con limitada extensión areal, indican preservación de depósitos de llanuras de inundación afectadas por recurrentes desbordes y migración de canales secundarios (Collinson, 1996). Las evidencias de pedogénesis indican que en forma esporádica existieron períodos con tasas de sedimentación extremadamente bajas en la llanura de inundación (cf. Kraus, 1999). Los paleosuelos y bancos de carbón se relacionan con paleopendientes exiguas, desarrolladas entre las fajas de canales o en sectores de la llanura de inundación estable.

\section{Composición de conglomerados}

A pesar del fuerte predominio de la composición granítica de los conglomerados de la Formación Las Pircas y de la naturaleza arcósica de su matriz, se advierte una variación composicional acentuada desde la sección inferior hasta el tope (Fig. 6), sugiriendo una exhumación gradual del área fuente. No obstante, los mayores cambios ocurren en relación con su yacencia.

En Bordo Atravesado y en las quebradas de los ríos Cosme y Las Pircas, sobre la ladera occidental de Famatina, así como en el anticlinal Los Colorados sobre la vertiente oriental, los conglomerados de la sección inferior de esta unidad se componen casi exclusivamente de clastos y bloques graníticos (Granitos ordovícicos Nuñorco y Paimán). En estos parajes, la unidad presenta hacia el tope un aumento continuo en la proporción de clastos volcánicos ordovícicos (Grupos Famatina y Cerro Morado). Asimismo, una pequeña proporción está constituida por clastos de areniscas blancas, del Pensilvaniano Inferior (Formación Agua Colorada).

En el yacimiento La Mexicana la sección basal presenta una predominancia de bloques graníticos ordovícicos bien redondeados (Granito Nuñorco) y una alta participación de clastos de metapelitas y metaareniscas de la subyacente Formación Achavil. Hacia el tope se incrementan progresivamente los clastos graníticos hasta alcanzar proporciones superiores al 95\%. En Casa Blanca, sobre la ladera oriental de Famatina, en la composición de los conglomerados basales se destaca un alto porcentaje de areniscas blancas de la subyaciente Formación Agua Colorada (Fig. 7) y de sedimentitas cambro-ordovícicas, mostrando un incremento en el contenido de clastos volcánicos hacia el techo. En las nacientes del río Blanco la composición de los conglomerados muestra un predominio de volcanitas ordovícicas y valores subordinados de sedimentitas ordovícicas, de la Formación Agua Colorada y de rocas graníticas ordovícicas.

La variación composicional de los conglomerados indica una heterogeneidad del sustrato (ver Paleogeografía) y el progresivo destechado del área fuente ('unroofing'); en algunas regiones caracterizadas por la eliminación de estratos pensilvanianos hasta alcanzar las sucesiones volcanosedimentarias y los plutones ordovícicos que forman parte del basamento de la región. Además, la participación de clastos de la Formación Agua Colorada implica un reciclado del sustrato que habría alcanzado a litificarse y vuelto a exponer en el área fuente. Esto es propio de fenómenos de canibalización asociados a tectónica activa. 


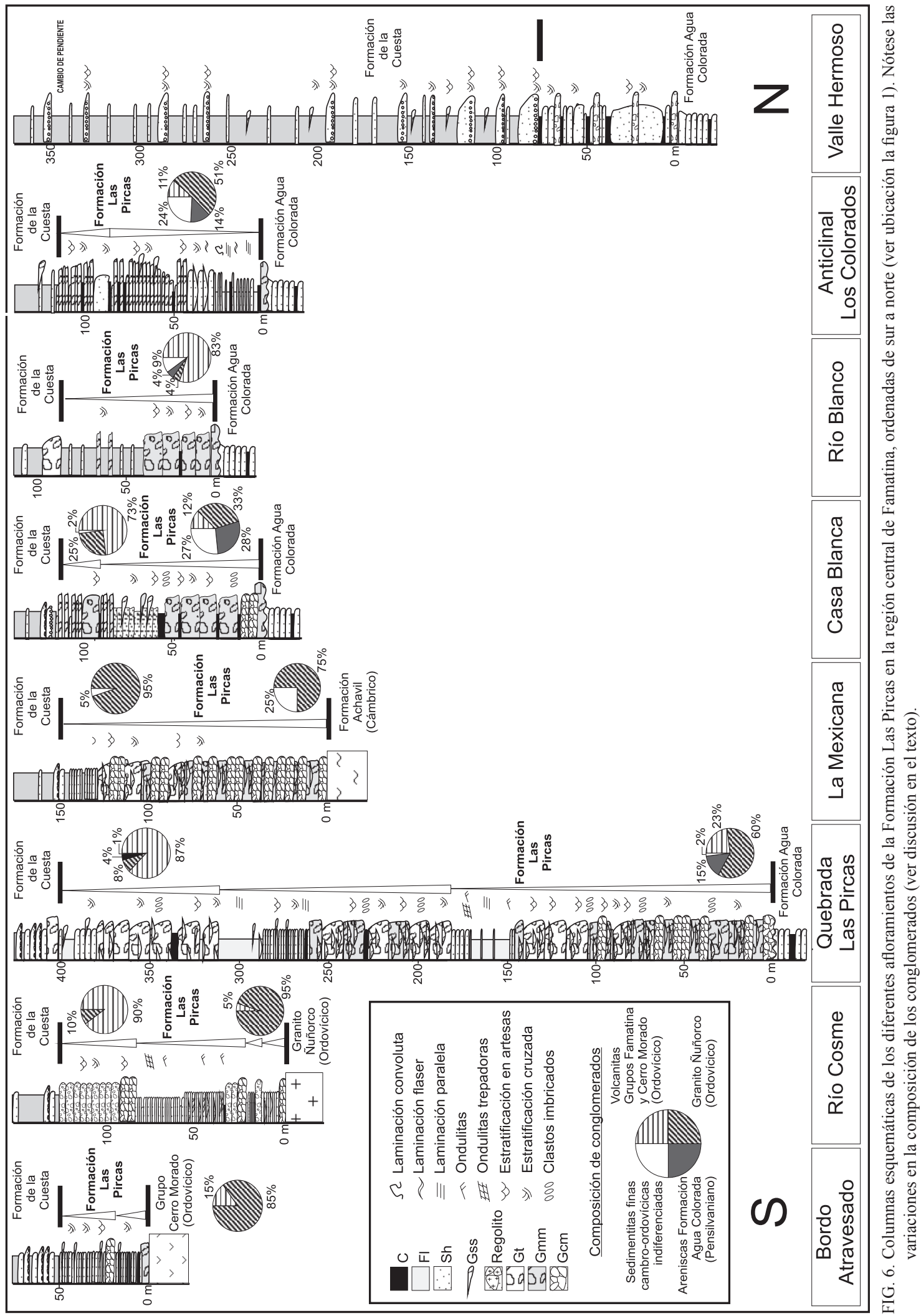




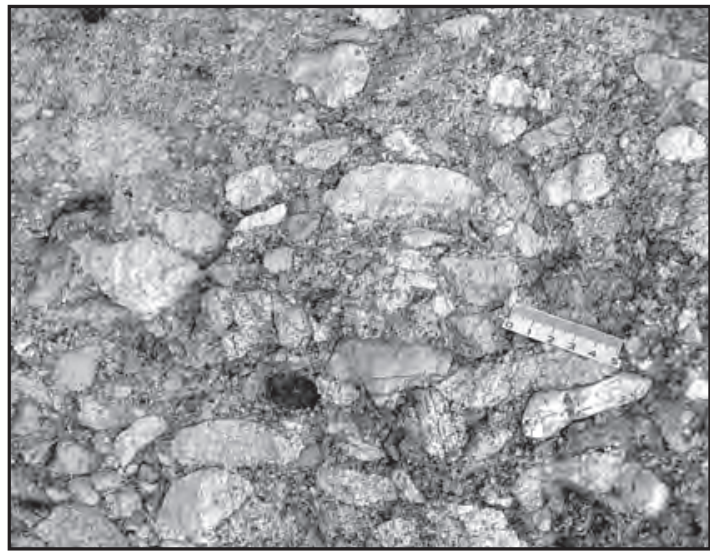

FIG. 7. Detalle de la composición de la sección basal de la Formación Las Pircas en Casa Blanca. Nótese el alto contenido de clastos de areniscas blancas provenientes de la infrayacente Formación Agua Colorada.

\section{Arreglo vertical y evolución paleoambiental}

Pueden diferenciarse tres megaciclos caracterizados por un salto granulométrico relativamente abrupto en la base, seguidos por sucesiones granodecrecientes que culminan con depósitos fluviales areno-limosos representando sistemas de menor gradiente. En su estratotipo (Fig. 5), la Formación Las Pircas se inicia con $140 \mathrm{~m}$ de conglomerados correspondientes a la asociación de facies de conglomerados desorganizados evidenciando proximidad a un fuerte relieve y depósitos de abanicos aluviales proximales (Nemec y Postma, 1993). Los conglomerados de la sección inferior están dominados por flujos gravitacionales e indican el primer pulso de avance aluvial sobre el sustrato paleozoico. Internamente presentan autociclos granodecrecientes de menor espesor (5-15 m), con depósitos carbonosos intercalados. La presencia de truncamientos angulares intraformacionales (Fig. 8) asociados a estos autociclos menores, indicaría migración lateral de sistemas trinchera-lóbulo activo. Por encima de esta sucesión dominantemente conglomerádica se observa una transición a una asociación de facies fluvial arenosa con particiones pelíticas y material carbonoso de $30 \mathrm{~m}$ de espesor, evidenciando una etapa de tranquilidad y reducción en el aporte psefítico, que habría favorecido el desarrollo de vegetación y paleosuelos (Fig. 3f). Por encima de esta sucesión fluvial aparecen $90 \mathrm{~m}$ de conglomerados que marcan un nuevo cambio en la pendiente depositacional y en la tasa de sedimentación. Esta sucesión psefítica es semejante a la expuesta en la base conteniendo megacapas con bloques. El contacto neto de esta cuña conglomerádica puede interpretarse como una expansión rápida de abanicos aluviales hacia regiones marginales de menor pendiente. Localmente, esta sucesión presenta depósitos de mantos de crecida con alto contenido de material carbonoso redepositado en sectores proximales a medios de un abanico aluvial que han quedado preservados con geometrías cuneiformes e intervalos de escasa continuidad lateral entre paquetes psefíticos. Estos intervalos podrían asociarse con autociclicidad del sistema aluvial. A estos conglomerados les sucede una asociación de facies fluviales con paleosuelos $(30 \mathrm{~m})$. El tercer ciclo granodecreciente comienza con un abrupto pasaje a conglomerados de guijones clastosoportados característicos de sistemas fluviales entrelazados gravosos (Fig. 5c). Esto marcaría una nueva etapa de proyección y traslape rápido de sucesiones psefíticas, y una posterior retrogradación del sistema.

El arreglo vertical granoestratodecreciente (Fig. 5) de toda la unidad, indicado por la mayor participación de flujos gravitacionales y procesos de baja eficacia de transporte en la porción inferior de la formación, es consistente con abanicos aluviales con alto gradiente a los que progresivamente suceden depósitos con dominios de flujos fluidales característicos de abanicos de mayor eficacia. A esta escala, este cambio en los procesos sedimentarios dominantes se vincularía con una disminución progresiva de la pendiente regional.

En el estratotipo, mediante una relación de paraconcordancia suprayace una sucesión de areniscas y pelitas rojizas bien estratificadas, con geometrías tabulares pertenecientes a la Formación de la Cuesta. Esta unidad solapa en toda la región central de Famatina tanto la Formación Las Pircas como unidades más antiguas incluyendo el basamento granítico, evidenciando una discordancia regional. La marcada homogeneidad litofacial de los depósitos basales de la Formación de la Cuesta a nivel regional (López Gamundí et al., 1994), junto al pobre desarrollo de conglomerados basales, indican escasez de paleorrelieve para el momento de su depositación, hecho que permite interpretar un progresivo proceso de planación de las topografías que dominaron el sistema depositacional de la Formación Las Pircas. 


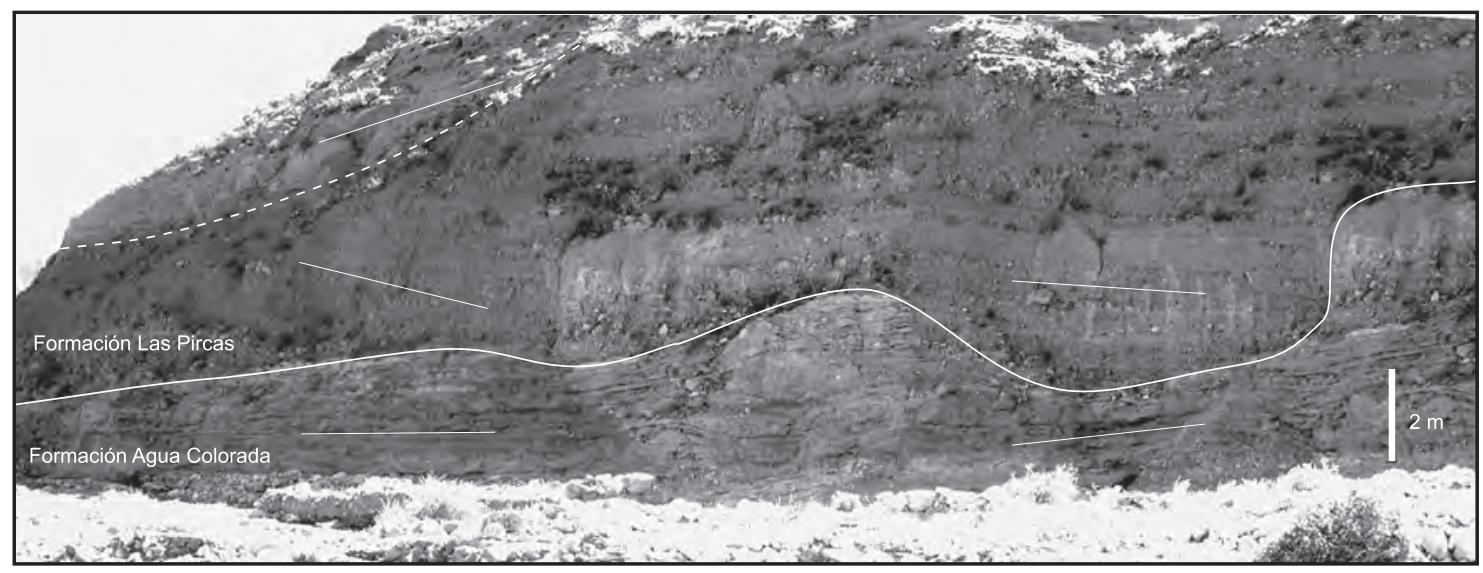

FIG. 8. Discontinuidad intraformacional (línea de puntos) en la base de la Formación Las Pircas en su estratotipo.

\subsection{Variaciones laterales de la Formación Las Pircas}

Si bien la Formación Las Pircas se caracteriza por estratos psefíticos de abanicos aluviales, existen marcadas variaciones litofaciales y de espesores entre los diferentes afloramientos de esta unidad en la región (Fig. 6). En Bordo Atravesado, sobre la vertiente occidental de la sierra de Famatina, la unidad presenta una tendencia general granodecreciente, $\mathrm{y}$ se encuentra dominada por depósitos conglomerádicos de sistemas fluviales entrelazados. Se destaca un nivel próximo a la base con bloques graníticos sobredimensionados de hasta $5 \mathrm{~m}$ (en su eje a), bien redondeados. Localmente, se encuentran intercalados mantos carbonosos con alto contenido detrítico. En el río Cosme, se observan cuatro pulsos granodecrecientes, que individualmente alcanzan $c a .30 \mathrm{~m}$ de espesor, con una mayor proporción de depósitos fluviales-lacustres. En esta sección, los paquetes psefíticos se encuentran dispuestos en forma de cuñas que describen marcados saltos granulométricos respecto a las asociaciones de facies más finas. En la región próxima al yacimiento de La Mexicana, sobre la ladera oriental de Famatina, la Formación Las Pircas está representada por facies de abanicos aluviales proximales dominados por flujos gravitacionales con bloques de composición granítica de hasta $2 \mathrm{~m}$ y presenta una tendencia general granodecreciente. En Casa Blanca se distinguen dos pulsos de avance similares a los descritos en el estratotipo, dominados por facies de abanico aluvial dominados por corrientes tractivas. En río Blanco se observa un arreglo general granodecreciente, que comienza con facies aluviales proximales en la base que pasan transicionalmente a niveles más finos, típicos de un sistema fluvial donde prevalecen depósitos de la llanura de inundación. En esta sección, los cambios sucesivos en el buzamiento de la estratificación indican un 'abanicamiento' del registro que es interpretado como una discordancia progresiva (Anadon et al., 1986; Fig. 9). En el anticlinal Los Colorados se observa un arreglo granocreciente que comienza con depósitos lacustres, seguidos de facies de sistemas fluviales entrelazados y coronados por facies de conglomerados gruesos. Este arreglo es consistente con un modelo progradacional de 'fan delta', donde como expresión distal de abanicos se desarrollan cuerpos lacustres.

Los marcados cambios de espesores y de asociaciones de facies observados en los diferentes afloramientos de la Formación Las Pircas sugieren la existencia de un paleorrelieve irregular durante la depositación de esta unidad.

\section{Distribución de paleocorrientes y patrones de dispersión}

Los datos de paleocorrientes fueron tomados sobre superficies interpretadas como caras de avalancha, clastos imbricados a(t)-b(i) y en ondulitas de corriente, y muestran una importante dispersión de las paleocorrientes con una dirección general hacia el noroeste-oeste (Fig. 10).

En la región septentrional del área de estudio las paleocorrientes indican una dirección predomi- 


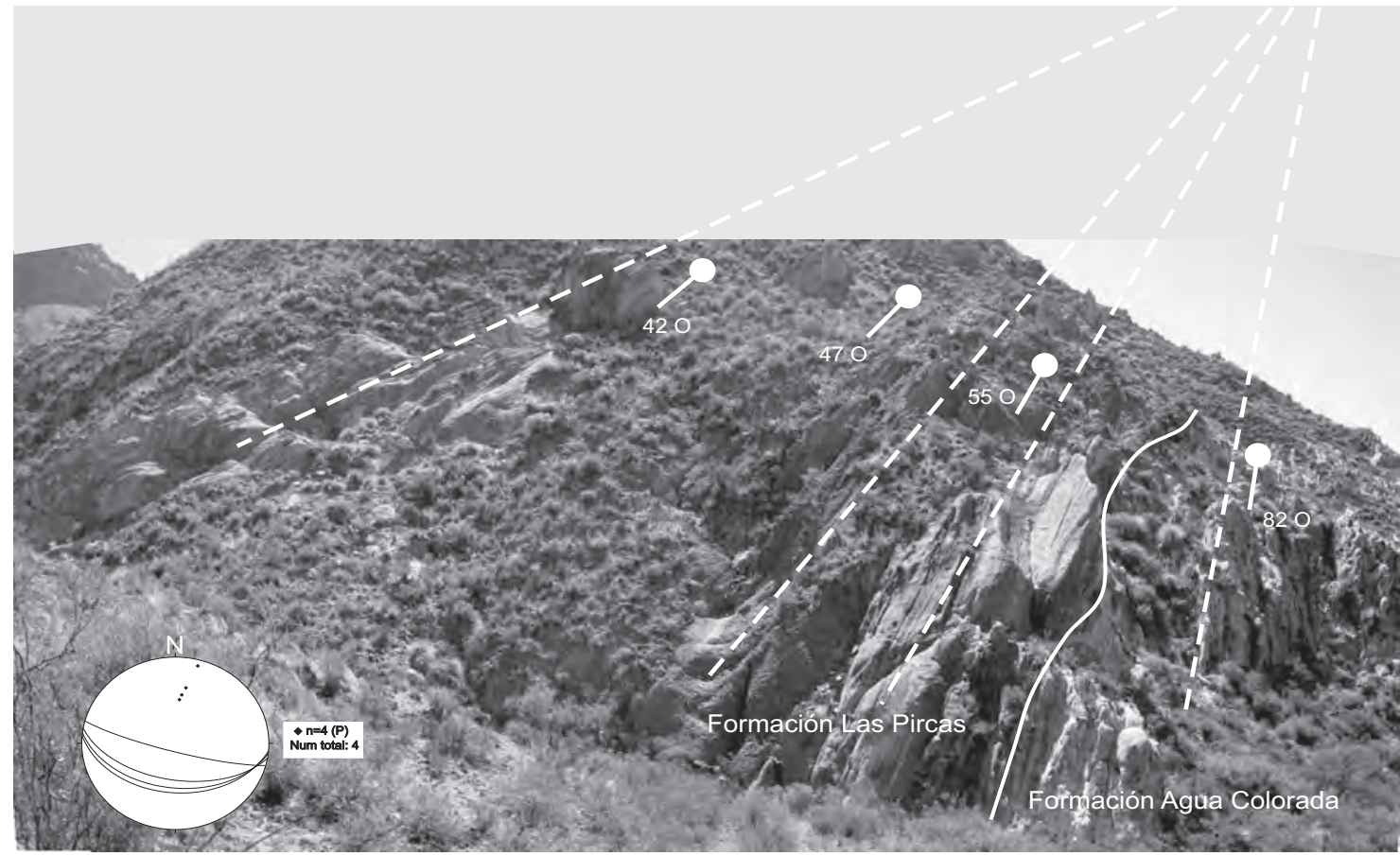

FIG. 9. Vista panorámica de la Formación Las Pircas mostrando las discordancias progresivas sobre el perfil del Río Blanco (margen N). Obsérvese el 'abanicamiento' de la estratificación en un patrón rotatorio. En el margen inferior izquierdo, se observa una red estereográfica equiareal con los polos promedio de la estratificación.

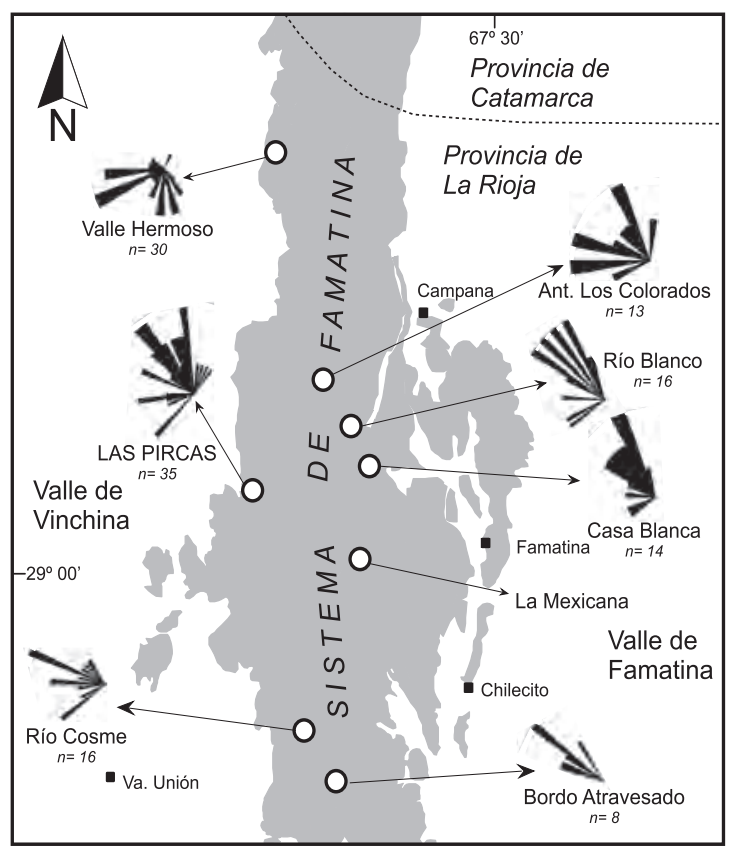

FIG. 10. Análisis de paleocorrientes de la Formación Las Pircas, indicando una dispersión hacia el oeste. En la región norte las paleocorrientes indican una dirección predominante hacia el NO. En la región sur las paleocorrientes tienen una dirección general hacia el oeste-noroeste. nante hacia el NO. En la quebrada Las Pircas, las paleocorrientes medidas se orientan en sentidos predominantes hacia $320^{\circ}$ aunque, en menor medida, se desarrolla una moda secundaria con sentido NNO. Sobre la ladera oriental, en el puesto Casa Blanca, las paleocorrientes predominantes muestran una trayectoria $\mathrm{NO}\left(305^{\circ}\right.$ dirección promedio). Los afloramientos de Río Blanco y anticlinal Los Colorados poseen direcciones promedio muy similares $\left(312^{\circ}\right.$ y $299^{\circ}$, respectivamente). En cambio, en Valle Hermoso las paleocorrientes indican una dirección predominante al SO (con una dirección promedio $222^{\circ}$ ). Por su parte, las paleocorrientes sugieren que los depósitos ubicados en la región sur del área de estudio (Río Cosme y Bordo Atravesado) habrían estado dirigidos hacia el oeste, con una dirección promedio hacia $280^{\circ}$.

\section{Paleogeografía}

Aunque son numerosos los trabajos que abordaron la paleogeografía del Paleozoico superior del oeste argentino en forma regional (e.g., Salfity y Gorustovich, 1983; López Gamundí et al., 1994), pocos estudios de detalle han avanzado 
sobre el conocimiento particular de este intervalo en la región central de Famatina con el objeto de establecer precisiones paleogeográficas, a los efectos de mejorar el análisis de la cuenca y el marco evolutivo.

La figura 11a muestra los diferentes sustratos sobre los que yace la Formación Las Pircas en la zona de estudio y la naturaleza de los contactos. Al sur la unidad solapa directamente al basamento cambro-ordovícico (Formación Achavil, Grupo Cerro Morado y granitoides tipo Nuñorco), y hacia el norte se apoya en discordancia con angularidad variable sobre las sedimentitas pensilvanianas tempranas a medias de la Formación Agua Colorada. Esto indica una discordancia regional y compartimentación del sustrato previo a la depositación de la unidad. Las discordancias angulares basales indican que una etapa de deformación involucró incluso a la Formación Agua Colorada. La distribución areal discontinua y los espesores variables de la Formación Las Pircas permiten interpretar que esta unidad se desarrolló sobre un relieve joven e irregular y que la estructuración de la región ocurrió inmediatamente antes de su depositación. En la figura $11 \mathrm{~b}$ se observan las variaciones en el tamaño máximo de clastos de la Formación Las Pircas, que puede considerarse como una medida de la distancia al área fuente. Las granulometrías disminuyen gradualmente hacia el NO en la dirección de las paleocorrientes dominantes. Las sedimentitas más gruesas se encuentran en las regiones central y sur, donde la Formación Las Pircas se apoya sobre el basamento, especialmente en su localidad tipo. El mayor distanciamiento a la fuente evidenciado por el paulatino incremento de facies aluviales medias y distales sumado a la mayor variedad de la composición, sugiere un incremento del área de captura de la red de drenaje y una pérdida gradual del relieve para el momento en que se depositaba la sección superior de la Formación Las Pircas.

\section{Correlación regional}

Aunque estudios palinológicos en la Formación Las Pircas indican, por el momento, ausencia de niveles fértiles, las muestras de la sección superior de la Formación Agua Colorada marcan una edad pensilvaniana temprana a media (Bashkiriano-

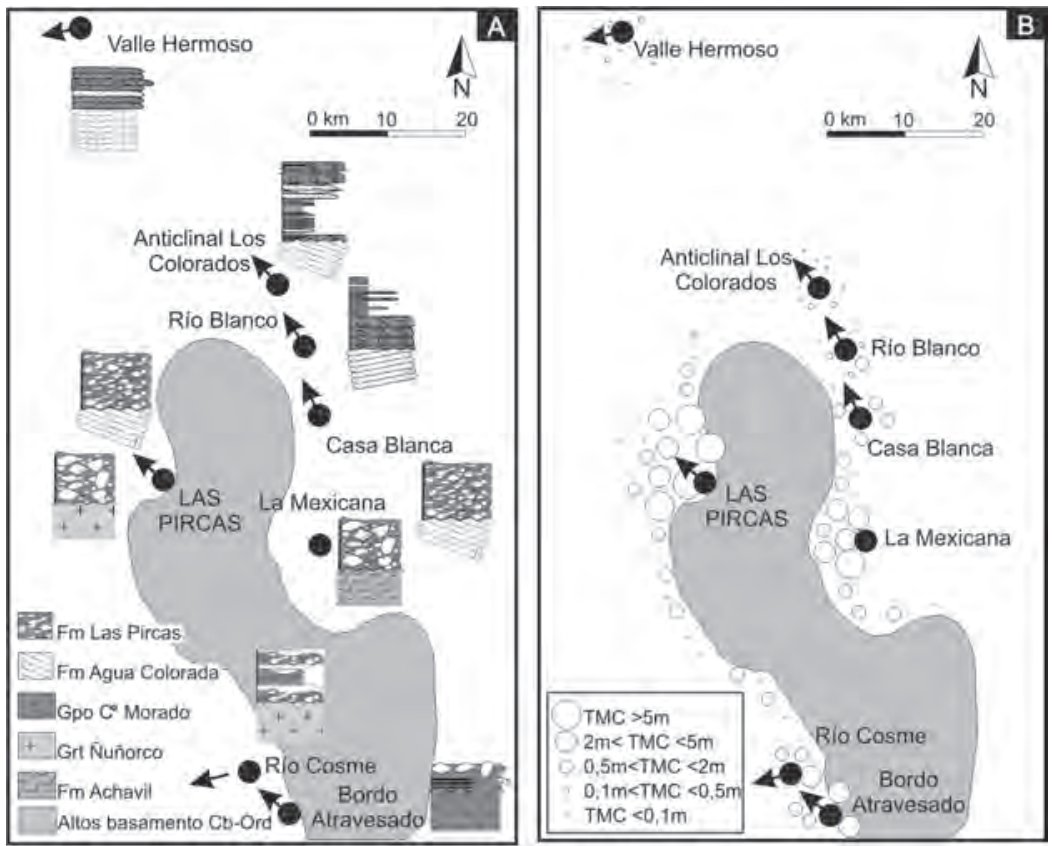

FIG. 11. A. Relación estratigráfica de la Formación Las Pircas con los diferentes sustratos. El área gris representa los altos de basamento para el momento de depositación de la Formación Las Pircas (ídem para figura 11b); B. Mapa esquemático en el que se observan las tendencias granulométricas generales de la Formación Las Pircas en la región. Los círculos blancos muestran los diferentes rangos en los tamaños máximos de clastos (TMC) de capas individuales. 
Moscoviano) por la presencia de la Biozona de Asociación Raistrickia densa-Convolutispora muriornata (DM) y más específicamente indican una posición más alta que la Sub-biozona de Intervalo A (Ezpeleta y Gutiérrez, 2006). Esta asociación palinológica es correlacionada con la trasgresión postglacial pensilvaniana (Limarino et al., 2002) y representaría un límite de edad máxima para la Formación Las Pircas. La presencia de bancos carbonosos asociados a facies fluviales similares a los descritos en las formaciones Tupe y Río del Peñón, permitiría establecer una correlación litoestratigráfica relativamente confiable basada en criterios estratigráficos secuenciales (cf. López Gamundí et al., 1992, 1994; López Gamundí y Martínez, 2003). La Formación Tupe se encuentra en la región más occidental de la cuenca de Paganzo, y muestra un arreglo granodecreciente que comienza con facies de arcosas conglomerádicas que pasan hacia el techo a bancos psamíticos intercalados con pelitas intensamente bioturbadas, interpretándose como el pasaje de ríos entrelazados areno-gravosos a sistemas fluviales meandriformes (López Gamundí et al., 1994). En los afloramientos de Río Cosme y Bordo Atravesado las paleocorrientes de la Formación Las Pircas tienen una dirección dominante al oeste y sugieren una continuidad lateral con los sistemas fluviales de la Formación Tupe. Asimismo, los afloramientos septentrionales de la Formación Las Pircas (Fig. 10) indican paleocorrientes al NO, hecho que permite sugerir una continuidad lateral con cuñas areno-conglomerádicas rosadas intercaladas en el miembro medio de la Formación Río del Peñón desarrollada en la parte septentrional de la cuenca Río Blanco y expuesta al oeste de la Precordillera. Esta última unidad marca el avance hacia el oeste de un sistema deltaico (Scalabrini Ortiz y Arrondo, 1973), alimentado desde la región de las Sierras Pampeanas donde dominan las fuentes graníticas. Tanto la Formación Tupe como parcialmente la Formación Río del Peñón, representarían equivalentes distales en la antefosa de los sistemas aluviales proximales representados en la Formación Las Pircas. Las edades de estas unidades están bien definidas a partir de registros palinológicos y de invertebrados fósiles, pudiendo circunscribirse al límite Pensilvaniano superior-Pérmico inferior (Gzelhiano-Asseliano, Sterren, 2000; Cisterna et al., 2002).

\section{Contexto tectonosedimentario}

Trabajos anteriores consideraron el intervalo equivalente de la Formación Las Pircas como el relleno de paleorrelieves heredados de la glaciación gondwánica, durante una etapa de tranquilidad tectónica (e.g., López Gamundí y Breitkreuz, 1997; Azcuy et al., 1999; Limarino et al., 2006). Esto se debe a que no fueron diferenciadas las facies conglomerádicas de clara connotación glacial, rellenando paleovalles, de aquellas que indican tectonismo. El importante salto granulométrico con la unidad subyacente, la recurrencia de megacapas con bloques, junto a la presencia de discontinuidades intraformacionales y progresivas en la Formación Las Pircas, sugiere una etapa de deformación coetánea con la depositación de la unidad. El incremento granulométrico en comparación con la Formación Agua Colorada y la predominancia de clastos graníticos en la base de la Formación Las Pircas, indica que el basamento fue directamente involucrado durante la sedimentación de esta unidad. Su yacencia discordante con ángulos variables (de hasta $80^{\circ}$ en el anticlinal de Los Colorados), que presenta en toda la región central de Famatina, sustenta un episodio de deformación independiente y posterior al fenómeno glacial. En este sentido vale destacar que en Casa Blanca una suave discordancia angular separa la Formación Las Pircas de la Formación Agua Colorada que se encuentra localizada dentro de un paleovalle glacial (Ezpeleta y Astini, 2005). En esta localidad la Formación Las Pircas cuenta con abundantes clastos de la infrayacente unidad, indicando un reciclado tectónico.

El salto granulométrico abrupto que representan los depósitos más gruesos y desorganizados en la base de cada ciclo depositacional de la Formación Las Pircas, indica un corrimiento relativamente rápido de cuñas conglomerádicas sinorogénicas acompañadas de una posterior expansión de los sistemas aluviales con fuentes localizadas en regiones de basamento. Esta rápida expansión areal de los depósitos conglomerádicos se habría vinculado con cambios en la pendiente general y exhumación de altos de basamento, permitiendo un desarrollo asimétrico de las cuñas conglomerádicas superando la tasa de acomodación. Posteriormente y debido a un progresivo incremento en las tasas de subsidencia en las regiones proximales, la asociación de facies 
de conglomerados desorganizados se corre hacia la escarpa activa permitiendo explicar el desarrollo areal más restringido y la asimetría de esta cuña conglomerádica de composición dominantemente granítica que grada a depósitos fluviales arcósicos. Diferentes estudios relacionan secuencias granodecrecientes con períodos tectónicamente activos (e.g., Heller et al., 1988; Burbank et al., 1988), donde los depósitos psefíticos se retraen hacia el frente montañoso al incrementarse la subsidencia por carga localizada. Si bien los arreglos granoestratodecrecientes han sido interpretados alternativamente como indicativos de contextos tectónicos extensionales o compresionales (Dávila y Astini, 2003), poco énfasis ha sido puesto en la naturaleza de base de las cuñas conglomerádicas. En contraste con los sistemas extensionales donde la creación de espacio de acomodación es repentina e inducida por rotación de bloques (Gawthorpe y Leeder, 2000), en el caso de la Formación Las Pircas el arreglo espacial de las cuñas conglomerádicas indica un reducido espacio de acomodación inicial. Esto podría ser mejor explicado dentro de un contexto compresivo, donde el espacio de acomodación inducido por flexura tiene una respuesta más lenta, incluso en un modelo elástico. Así, en un ambiente continental, es previsible un avance más rápido de la cuña conglomerádica con un traslape evidente sobre asociaciones de facies contrastadas. Esto es consistente con estudios estructurales realizados en el anticlinal Los Colorados (Dávila et al., 2003; Dávila, 2003), que sugieren una etapa compresiva con plegamiento asimétrico y vergencia al este durante el intervalo estratigráfico considerado.

La posición del área fuente dentro del antepaís, las tendencias granulométricas y las direcciones de paleocorrientes, permitirían descartar un aporte desde las regiones cordilleranas actuales. Este contexto estratigráfico difiere de un modelo de antepaís flexural simple (cf. DeCelles y Giles, 1996), donde el aporte principal es desde las regiones internas ('hinterland'). La progradación hacia el oeste del sistema aluvial de la cuenca de Paganzo sobre las secciones marinas de las cuencas coetáneas de Calingasta-Uspallata y Río Blanco, indica el comienzo de la colmatación del depocentro cordillerano que posiblemente esté vinculado con suministros predominantes desde la región de Famatina representados por la Formación Las Pircas (Fig. 12). Esto sugiere la finalización del período subalimentado y una transición hacia la etapa de sobrealimentación dominante en la historia tardía neopaleozoica del oeste argentino.

El conjunto de evidencias aportadas en este trabajo permite interpretar un episodio de deformación de zócalo y desarrollo de una fragmentación en el antepaís afectando la actual región de Sierras Pampeanas y Sierra de Famatina durante el límite Pensilvaniano-Pérmico (Ezpeleta et al., 2005; Fig. 12). Este modelo difiere de las interpretaciones previas (Salfity y Gorustovich, 1983; López Gamundí et al., 1994; Limarino et al., 2006), donde no se reconoce una etapa de estructuración tectónica importante asociada a cuñas conglomerádicas descritas en este trabajo (Formación Las Pircas). Estos conglomerados asociados a una discordancia basal de magnitud regional, permiten establecer una correlación entre la región cratónica tradicionalmente denominada cuenca de Paganzo (dominio oriental) con la estratigrafía de la antefosa representada en la cuenca de Río Blanco (dominio occidental). En el marco regional, estas regiones contiguas pueden interpretarse como depozonas adyacentes dentro de una cuenca de antepaís de retroarco. Aunque los estadios de antepaís fragmentado han sido tradicionalmente vinculados con subducción subhorizontal (e.g., Jordan y Allmendinger, 1986; Ramos et al., 2002; Dávila y Astini, 2007) y documentados en la historia andina cenozoica, es posible que las evidencias presentadas en este trabajo indiquen una etapa de fragmentación más temprana. Existen a la fecha escasos estudios del magmatismo pericratónico asociado (Astini et $a l ., 2005)$ que permitan evaluar de manera independiente este modelo sugerido a partir de la evidencia estratigráfica.

\section{Conclusiones}

El análisis de una cuña sinorogénica conglomerádica interpuesta entre las clásicas unidades de la cuenca de Paganzo, denominada Formación Las Pircas, permite interpretar el contexto tectonoestratigráfico del Paleozoico superior en la región centro-oeste de Argentina. Esta nueva unidad litoestratigráfica se apoya en discordancia alternativamente sobre la sucesión tardío-glacial pensilvaniana (Formación Agua Colorada) o sobre el basamento cambro-ordovícico, y es cubierta en forma concordante por las areniscas rojas fluvio-eólicas de edad pérmica (Formación de la Cuesta).

En esta unidad se diferenciaron cuatro asociaciones de facies: a. asociación de facies conglo- 


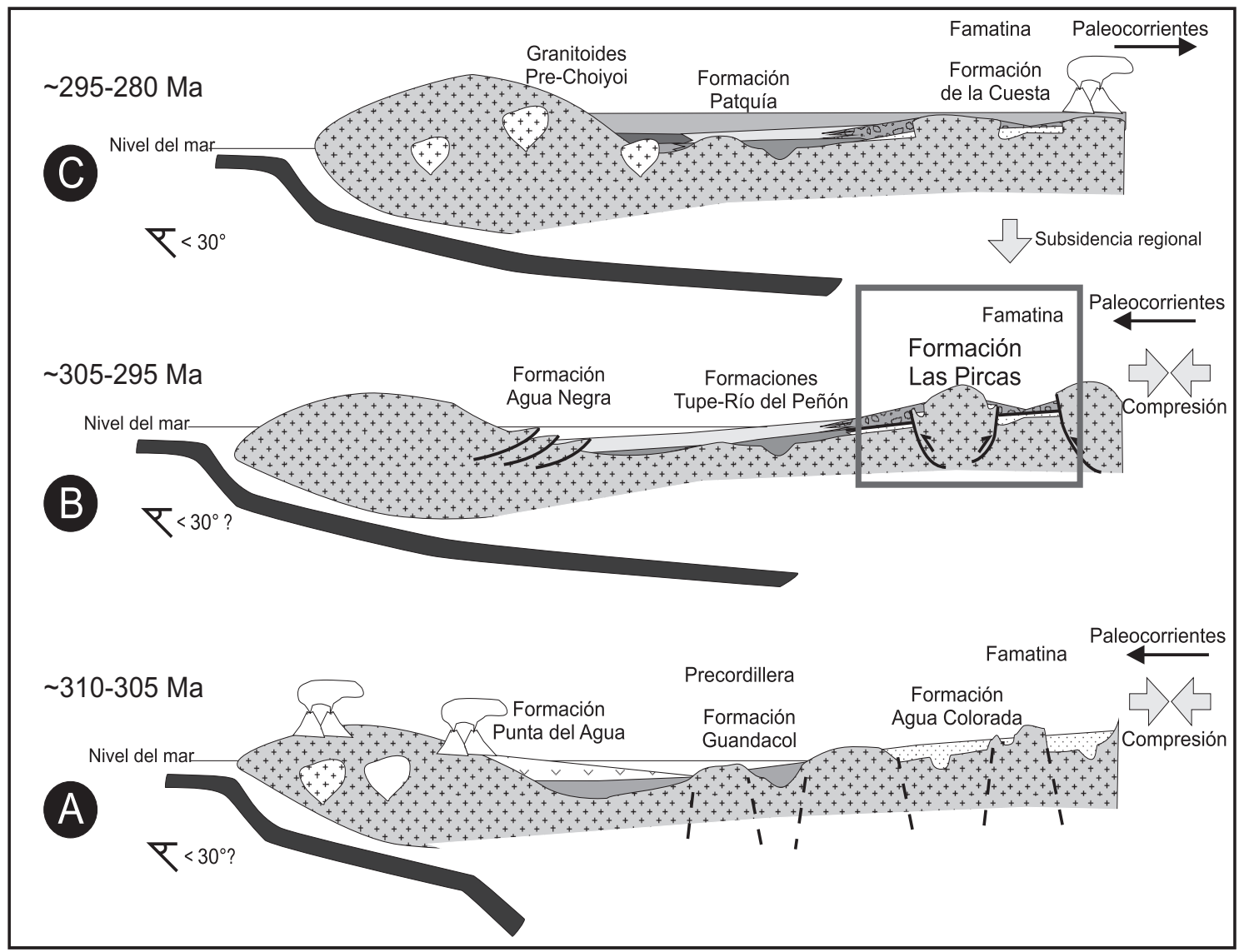

FIG. 12. Evolución tectosedimentaria de la cuenca de Paganzo entre los 28 y $29^{\circ} \mathrm{S}$. A. En el antepaís hay una disminución del relieve heredado de la glaciación gondwánica (Bahskiriano) y depositación de las sucesiones fluviales postglaciales (Formación Agua Colorada). El arco volcánico está representado por la Formación Punta del Agua (González y Bossi, 1986); B. Deformación de zócalo y exhumación de altos de basamento en la región de Famatina (recuadro). Depositación sinorogénica de la cuña conglomerádica de la Formación Las Pircas y sus equivalentes laterales (formaciones Tupe y Río del Peñón). Antepaís fragmentado, posiblemente relacionado con una disminución en el ángulo de la loza que subduce, como sugiere la ausencia de volcanismo. La faja corrida y plegada está evidenciada por sucesiones granoestratocreciente en la Formación Agua Negra (Busquets et al., 2005); C. Subsidencia regional en el antepaís evidenciada por depósitos fluviales y eólicos de la Formación de la Cuesta, que nivelan la topografía. Una inversión regional de la pendiente se deduce por el cambio de las paleocorrientes dominantes. Volcanismo ubicado en el interior de la región Pampeana (Astini et al., 2005) y emplazamiento de granitoides pre-Choiyoi al oeste (e.g., Llambías y Sato, 1990).

merádicas desorganizadas, dominada por flujos de gravedad y flujos de detritos que indican abanicos aluviales proximales y de alto gradiente; b. asociación de facies conglomerádicas organizadas, característica de sistemas fluviales entrelazados gravosos; c. asociación de facies pelíticas y areniscas tabulares gradadas de ambientes lacustres y $\mathbf{d}$. asociación de facies de areniscas y conglomerados indicativa de sistemas fluviales multiepisódicos. El notable predominio de la primera asociación permite interpretar un ambiente de abanicos aluviales con alto gradiente y pasajes progresivos a depósitos con dominio de flujos fluidales propios de abanicos de mayor eficacia. El ordenamiento estratigráfico permite diferenciar tres megaciclos granodecrecientes caracterizados por un salto granulométrico abrupto en la base.

La predominancia de clastos de granitos y volcanitas ordovícicas similares a los expuestos actualmente en las Sierras Pampeanas (incluyendo El Famatina), y las paleocorrientes hacia el noroeste y oeste, indican que durante la depositación de la 
Formación Las Pircas el área fuente se encontraba en la región externa del antepaís, lo que lleva a descartar un episodio de progradación conglomerádico desde el arco. Las características granulométricas y composicionales son consistentes con una fuerte denudación inducida por tectonismo.

Las relaciones estratigráficas y paleogeográficas de la unidad dentro del cinturón de Famatina, indican que la Formación Las Pircas representa los depósitos más proximales de una cuña clástica pensilvaniana tardía-pérmica temprana que tiene como equivalentes distales las sucesiones fluvio-deltaicas de las formaciones Tupe y Río del Peñón hacia el oeste. La progradación desde la región cratónica hacia la antefosa, de esta secuencia continental sobre sedimentitas marinas de las cuencas Calingasta-Uspallata y Río Blanco, indica la expansión de la cuenca de Paganzo. Esta habría ocurrido durante una etapa de deformación que produjo la exposición de altos de basamento en la región de Famatina, vinculada a una etapa de fragmentación del antepaís no reconocida con anterioridad.

\section{Agradecimientos}

Se agradece al geólogo J.C. Candiani (Servicio Geológico Minero Argentino, SEGEMAR) y a los estudiantes N. Swedowicz y A. Garrone (Universidad Nacional de Córdoba, Argentina) por la asistencia brindada durante el desarrollo de las tareas de campo. Este estudio es subsidiado por la Agencia Nacional de Promoción Científica y Tecnológica (ANPCyT-Argentina, PICT 07-11741, PICT 07-33060), la Secretaría de Ciencia y Tecnología (SECyT-Argentina, 197/05), el Consejo Nacional de Ciencia y Tecnología (CONICET-Argentina PIP 5783) y The International Association of Sedimentologist (IAS Grant Scheme, 2006).

\section{Referencias}

Anadón, P.; Cabrera, L.; Colombo, F.; Marzo, M.; Riba, O. 1986. Syntectonic intraformational unconformities in alluvial fan deposits, eastern Ebro Basin margins (NE Spain). Special Publication of the International Association of Sedimentologist 8: 259-271.

Ashworth, P.J.; Best, J.L.; Jones, M.A. 2007. The relationship between channel avulsion, flow occupancy and aggradation in braided rivers: insights from an experimental model. Sedimentology 54: 497-513.

Astini, R.A. 1996. Las fases diastróficas del Paleozoico medio de la Precordillera del oeste argentino-Evidencias estratigráficas. In Congreso Geológico Argentino, No. 13, Actas 5: 509-526. Buenos Aires.

Astini, R.A. 1998. El Ordovícico en la región central de Famatina (provincia de La Rioja, Argentina): as- pectos estratigráficos, geológicos y geotectónicos. Revista de la Asociación Geológica Argentina 53: 445-460.

Astini, R.A.; Ezpeleta, M.; Martina, F.; Dávila, F.M. 2005. Las 'tobas pérmicas' de Olta (La Rioja): lapillitas acrecionales en el interior de la región pampeana. In Congreso Geológico Argentino, No. 16: 741-748. La Plata.

Azcuy, C.L.; Morelli, J.R. 1970. Geología de la comarca Paganzo-Amaná. El Grupo Paganzo. Formaciones que lo componen y sus relaciones. Revista de laAsociación Geológica Argentina 25: 405-429.

Azcuy, C.L.; Carrizo, H.A.; Caminos, R. 1999. Carbonífero y Pérmico de las Sierras Pampeanas, Famatina, Precordillera, Cordillera Frontal y Bloque de San Rafael. In Geología Argentina (Caminos, R.; editor). Instituto de Geología y Recursos Minerales, Anales 29: 261-318. Buenos Aires.

Blair, T.C. 1987. Sedimentary processes, vertical stratification and geomorphology of the Roaring River alluvial fan, Rocky Mountain National Park, Colorado. Journal of Sedimentary Petrology 57: 1-18.

Blair, T.C.; McPherson, J.G. 1994. Alluvial fans and their natural distinction from rivers based on morphology, hydraulic processes, sedimentary process, and facies assemblages. Journal of Sedimentary Research 64: 450-489.

Blikra, L.H.; Nemec, W. 1998. Postglacial colluvium in western Norway: depositional processes, facies, and paleoclimatic record. Sedimentology 45: 900-959.

Boardman, E.L. 1989. Coal Measures (Namurian and Westhphalian) Blackband Iron Formations: fossil bog iron ores. Sedimentology 36: 621-633.

Bodenbender, G. 1911. Constitución geológica de la parte meridional de la provincia de La Rioja y regiones limítrofes. República Argentina. Boletín de la Academia Nacional de Ciencias 19 (1): 2-211. Córdoba.

Bridge, J.S. 2003. Rivers and floodplains: Form, Processes and Sedimentary Record. Blackwell Science: 491 p. Oxford, UK.

Burbank, D.W.; Beck, R.A.; Raynolds, R.G.H.; Hobbs, R.; Tahirkheli, R.A.K. 1988. Thusting and gravel progradation in foreland basins: A test of post-thrusting gravel dispersal. Geology 16: 1143-1146.

Busquets, P.; Colombo, F.; Heredia N.; Sole de Porta, N.; Rodríguez Fernández, L.R.; Álvarez Marrón, J. 2005. Age and tectonostratigraphic significance of the Upper Carboniferous series in the basement of the Andean Frontal Cordillera: Geodynamic implications. Tectonophysics 399: 181-194.

Cisterna, G.A.; Simanaukas, T.; Archbold, N.W. 2002. Permian brachiopods from the Tupe Formation, San Juan Province, Precordillera, Argentina. Alcheringa 26: $177-200$.

Collinson, J.D. 1996. Alluvial Sediments. In Sedimentary Environments and Facies (Reading, H.G.; editor). Elsevier: 37-82. New York.

Collo, G. 2006. Caracterización petrográfica y ter- 
mobarométrica de las unidades con bajo grado de metamorfismo de la región central de Famatina. Tesis Doctoral (Inédita), Universidad Nacional de Córdoba: 262 p.

Colombo, F. 1992. Abanicos Aluviales. In Sedimentología (Arche, A.; editor). Consejo Superior de Investigaciones Científicas, Tomo I: 143-218. Madrid.

Dávila, F.M. 2003. Transecta estratigráfica-estructural a los 28 $30^{\prime}-28^{\circ} 54^{\prime}$ de Latitud Sur, sierra de Famatina, provincia de La Rioja, República Argentina. Tesis Doctoral (Inédita), Universidad Nacional de Córdoba: $516 \mathrm{p}$.

Dávila, F.M.; Astini, R.A. 2003. Early Middle Miocene broken foreland development in the southern Central Andes: Evidence for extension prior to regional shortening. Basin Research, 15: 379-396.

Dávila, F.M.; Astini, R.A.; Schmidt, C.J. 2003. Unravelling $470 \mathrm{~m} . \mathrm{y}$. of shortening in the Central Andes and documentation of Type 0 superposed folding, Famatina Ranges, Western Argentina. Geology 31: 275-278.

Dávila, F.M.; Astini, R.A.; Ezpeleta, M. 2005. Sucesiones lacustres postgondwánicas-preandinas en la región de Famatina (La Rioja y Catamarca). Revista de la Asociación Geológica Argentina 60 (1): 88-95.

De Alba, E. 1979. El Sistema de Famatina. Simposio de Geología Regional Argentina, No. 2, Actas 1: 349395. Córdoba.

DeCelles, P.G.; Giles, K.N. 1996. Foreland basin systems. Basin Research 8: 105-123.

DeCelles, P.G.; Gray, M.B.; Ridgway, K.D.; Cole, R.B.; Pivnik, D.A.; Pequera, N.; Srivastava, P. 1991. Controls on synorogenic alluvial-fan architecture, Beartooth Conglomerate (Paleocene), Wyoming and Montana. Sedimentology 38: 567-590.

Durand, F.R.; Vergel, M.M.; Lech, R.R. 1996. Las sedimentitas neopaleozoicas del Sistema de Famatina. In Geología del Sistema de Famatina (Aceñolaza, F.G.; Miller, H.; Toselli,A.; editores), Müncher Geologische Hefte (Reihe A Allgemeine Geologie) 19: 77-95. Munich.

Ezpeleta, M.; Astini, R.A. 2005. Relleno de un paleovalle glacial neopaleozoico en la región central de Famatina, La Rioja. In Congreso Geológico Argentino, No. 16, Tomo 4: 583-590. La Plata.

Ezpeleta, M.; Gutiérrez, P.R. 2006. Nuevos elementos de la microflora de la Formación Agua Colorada (Pensylvaniano), sistema de Famatina, La Rioja, Argentina. In Congreso Argentino de Paleontología y Bioestratigrafía, No. 9, Simposio del Paleozoico Superior, No. 4, Actas 1:183 p. Córdoba.

Ezpeleta, M.; Dávila, F.M.; Astini, R.A. 2005. Late Paleozoic foreland development through western Argentina. Gondwana 12 (1):149.

Fernández-Seveso, F.; Tankard, A. 1995. Tectonics and stratigraphy of the Late Paleozoic Paganzo Basin of Western Argentina and its regional implications. In Petroleum basins of South America (Tankard,
A.J.; Suárez, S.; Welsink, H.J.; editors). American Association of Petroleum Geologists Memoir 62: 285-301.

Fernández Seveso, F.; Pérez, M.A.; Brisson, I.E.; Álvarez, L.A. 1993. Sequence stratigraphy and tectonic analysis of the Paganzo Basin, western Argentina. In Congrès International de la Stratigraphie et Géologie du Carbonifére et Permien, No. 12, Actas 2: 223-260. Buenos Aires.

Frostick, L.E.; Lucas, P.M.; Reid, I. 1984. The infiltration of fine matrices into coarse-grained alluvial sediments and its implications for stratigraphical interpretation. Journal of the Geological Society of London 141 (6): 955-965.

Gawthorpe, R.L.; Leeder, M.R. 2000. Tectono-sedimentary evolution of active extensional basins. Basin Research 12: $195-218$.

González C.R.; Bossi, G.E. 1986. Los depósitos carbónicos al oeste de Jagüel, La Rioja. In Congreso Argentino de Paleontología y Bioestratigrafía No. 4, Actas 1: 231-236. Mendoza.

Gutiérrez, P.R. 1995. Nuevos registros paleoflorísticos para la Formación Agua Colorada, Carbonífero Superior, en el sector sudoriental de la sierra de Famatina, provincia de la Rioja, Argentina. Ameghiniana 32 (2): 111-128.

Hampton, M.A. 1979. Buoyancy in debris flow. Journal of Sedimentary Petrology 49: 753-758.

Heller, P.L.; Angevine, C.L.; Winslow, N.S.; Paola, C. 1988. Two-phase stratigraphic model of forelandbasin sequences. Geology 16: 501-504.

Hiscott, R.N.; James, N.P. 1984. Carbonate debris flows, Cow Head Group, western Newfoundland. Journal of Sedimentary Petrology 55 (5): 735-745.

Jordan, T.E.; Allmendiger, R.W. 1986. The Sierras Pampeanas of Argentina: a modern analogue of Laramide deformation. American Journal of Science 286: 737-764.

Kraus, M.J. 1999. Paleosols in clastic sedimentary rocks: their geologic applications. Earth Science Reviews 47: 41-70.

Kraus, M.J.; Hasiotis S.T. 2006. Significance of different modes of rhizolith preservation to interpreting paleoenvironmental and paleohydrologic settings: examples from Paleogene paleosols, Bighorn basin, Wyoming, U.S.A. Journal of Sedimentary Research 76: 633-646.

Lawson, D.E. 1982. Mobilization, movement and deposition of active subaerial sediment flows, Matanuska Glacier, Alaska. Journal of Geology 90: 279-300.

Limarino, C.O. 1987. Paleoambientes sedimentarios y paleogeografía de la sección inferior del Grupo Paganzo en el Sistema de Famatina. Anales de la Academia Nacional de Ciencias Exactas, Física y Naturales 39: 145-178.

Limarino, C.O.; Spalletti, L.A. 1986. Eolian permian deposits in west and northwest Argentina. Sedimentary Geology 49: 109-127. 
Limarino, C.O.; Fauqué, L.; Net, L. 1999. Análisis tectosedimentario de las cuencas Paganzo y Río Blanco, noroeste argentino. Ameghiniana 36 (4): 33.

Limarino, C.O.; Césari, S.N.; Net, L.I.; Marenssi, S.A.; Gutiérrez, P.R.; Tripaldi, A. 2002. The Upper Carboniferous postglacial transgression in the Paganzo and Río Blanco Basins (northwestern Argentina): facies and stratigraphic significance. Journal of South American Earth Sciences 15: 445-460.

Limarino, C.O.; Tripaldi, A.; Marenssi, S.; Fauque, L. 2006. Tectonic, sea-level, and climatic controls on Late Paleozoic sedimentation in the western basins of Argentina. Journal of South American Earth Sciences 22: 205-226.

Llambías, E.J.; Sato, A.M. 1990. El batolito de Colangüil (29-31 $\left.{ }^{\circ} \mathrm{S}\right)$ Cordillera Frontal de Argentina: Estructura y marco tectónico. Revista Geológica de Chile 17 (1): 89-108.

López, R.; Clerici, C. 1990. Nuevos depósitos de areniscas eólicas y lacustres en la Formación de la Cuesta (Pérmico del Sistema de Famatina). In Congreso Geológico Argentino, No. 9, Actas 2: 453-456. San Juan.

López Gamundí, O.R.; Breitkreuz, C. 1997. Carboniferous-to-Triassic evolution of the Panthalassan margin, southern South America. In Late Paleozoic and Early Mesozoic Circum-Pacific Events and their GlobalCorrelation(Dickins, J.M.;Zunyi, Y.; Hongfu, Y.; Lucas, S.G.; Acharyya, S.; editors). Cambridge University Press 10: 8-19. Cambridge.

López Gamundí, O.R.; Martínez, M. 2003. Esquema estratigráfico-secuencial para las unidades neopaleozoicas de la cuenca Calingasta-Uspallata en el flanco occidental de la Precordillera. Revista de la Asociación Geológica Argentina 58 (3): 367-382.

López Gamundí, O.R.; Álvarez, L.; Andreis, R.R.; Bossi, G.E.; Espejo, I.; Fernández Seveso, F.F.; Legarreta, L.; Kokogian, D.; Limarino, C.O.; Sessarego, H. 1989. Cuencas intermontanas. In Cuencas sedimentarias argentinas (Chebli, G.; Spalleti, L.; editores). Serie de Correlación Geológica 6: 123-168.

López Gamundí, O.R.; Limarino, C.O.; Césari, S.N. 1992. Late Paleozoic paleoclimatology of central west Argentina. Paleogeography, Paleoclimatology, Palaeocology 91: 251-261.

López Gamundí, O.R.; Espejo, I.S.; Conhagan, P.J.; Powell, P.J. 1994. Southern South America. In Permian-Triassic Pangean Basins and foldbelts along the Panthalassan margin of Gondwanaland (Veevers, J.J.; Powell, C.; editors). Geological Society of America Memoir 184: 281-329. Boulder.

Lunt, I.A.; Bridge, J.S; Tye, R.S. 2004. Aquantitative, three dimensional depositional model of gravelly braided rivers. Sedimentology 51: 377-414.

Menéndez, C.A.; González-Amicón, O.R. 1979. Nuevos elementos de la microflora carbónica de 'Las Pircas' (Formación Agua Colorada) sierra de Famatina, La Rioja. Ameghiniana 16: 65-79.

Miall, A.D. 1996. The Geology of fluvial deposits: sedi- mentary facies, basin analysis and petroleum geology. Springer Verlag Inc.: 582 p. Berlín.

Mpodozis, C.; Ramos, V. 1989. The Andes of Chile and Argentina. In Geology of the Andes and its relation to hydrocarbon and mineral resources (Ericksen, G.E.; Cañas, M.T.; Reinemund A.; editors). Circum-Pacific Council for Energy and Mineral Resources Earth Sciences Series 5: 59-90.

Mpodozis, C.; Kay, S.M. 1990. Provincias magmáticas ácidas y evolución tectónica de Gondwana, Andes chilenos $\left(28^{\circ}-31^{\circ} \mathrm{S}\right)$. Revista Geológica de Chile 17: 153-180.

Nemec, W.; Steel, R.J. 1984. Alluvial and coastal conglomerates: their significant features and some comments on gravelly mass-flow deposits. In Sedimentology of gravels and conglomerates (Koster, E.H.; Steel, R.J.; editors). Canadian Society of Petroleum Geologist Memoir 10: 1-32. Calgary.

Nemec, W.; Postma, G. 1993. Quaternary alluvial fans in southwestern Crete: sedimentation processes and geomorphic evolution. Special Publications International Association of Sedimentologist 17: 235-276.

Norris, R.D. 1994. Seismicity of the rockfalls and avalanches at Three Cascade Range Volcanoes: implications for seismic detection of hazardous mass movements. Bulletin of the Seismological Society of America 84 (6): 1925-1939.

Oesterlen, P.M.; Lepper, J. 2005. The Lower Karoo coal (k2-3) of the Mid-Zambezi basin, Zimbabwe: depositional analysis, coal genesis and palaeogeographic implications. International Journal of Coal Geology 61: 97-118.

Ollier, C.; Pain C. 1996. Regolith, Soils and Landforms. John Wiley and Sons: 316 p. London.

Olsen, H. 1989. Sandstone-body structures and ephemeral stream processes in the Dinosaur Canyon Member, Moenave Formation (Lower Jurassic), Utah, USA. Journal of Sedimentary Petrology 61: 207-221.

Parker, G. 1974. Contactos discordantes entre los Pisos Iy II de los estratos de Paganzo. Revista de la Asociación Geológica Argentina 29: 23-29.

Ramos, V.A. 2000. The Southern Central Andes. In Tectonic Evolution of South America. 31st. International Geological Congress America (Cordani, U.G.; Milani, E.J.; Thomaz Filho, A.; Campos, D.A.; editors). Fólio Produção Editorial, Gráfica e Programação Visual: 561-604. Rio de Janeiro.

Ramos, V.A.; Aleman, A. 2000. Tectonic evolution of the Andes. In Tectonic Evolution of South America. 31st. International Geological Congress America (Cordani, U.G.; Milani, E.J.; Thomaz Filho, A.; Campos, D.A.; editors). Fólio Produção Editorial, Gráfica e Programação Visual: 635-685. Rio de Janeiro.

Ramos, V.A.; Cristallini, E.O.; Pérez, D.J. 2002. The Pampean flat-slab of the Central Andes. Journal of South American Earth Sciences 15: 59-78.

Salfity, J.A.; Gorustovich, S.A. 1983. Paleogeografía de la cuenca del Grupo Paganzo (Paleozoico Superior). 
Revista de la Asociación Geológica Argentina 38 (3-4): 437-453.

Scalabrini Ortiz, J.; Arrondo, O.G. 1973. Contribución al conocimiento del Carbónico de los perfiles del Cerro Veladero y del Río del Peñón (Precordillera de La Rioja). Revista del Museo de La Plata, Sección Geología 8: 257-279.

Schultz, A.W. 1984. Subaerial debris flow deposition in the upper Paleozoic Cutler Formation, western Colorado. Journal of Sedimentary Petrology 54 (3): 759-772.

Schwertmann, U. 1993. Relations between iron oxides, soil color, and soil formation. In Soil Color (Bigham, J.M.; Ciolkosz, E.J.; editors). Soil Science Society of America, Special Publication 31: 51-69.

Slingerland, R.; Smith N.D. 2004. River avulsions and their deposits. Annual Review of Earth Planetary Science 32: 257-285.
Sloss, L.L. 1963. Sequences in the cratonic interior of North America. Geological Society of America Bulletin 74: 93-114.

Sterren, A.F. 2000. Moluscos bivalvos en la Formación Río del Peñón (Carbonífero Tardío-Pérmico Temprano), provincia de La Rioja, Argentina. Ameghiniana 37: 421-438.

Turner, J.C.M. 1960. Estratigrafía del tramo medio de la Sierra de Famatina y adyacencias, La Rioja. Boletín Academia Nacional de Ciencias 42: 77-126.

Turner, J.C.M. 1964. Descripción geológica de la Hoja 15C, Vinchina (provincias de Catamarca y La Rioja). Dirección Nacional de Geología y Minería, Boletín 100: 81 p. Buenos Aires.

Turner, J.C.M. 1971. Descripción geológica de la Hoja 15d, Famatina (provincias de Catamarca y La Rioja). Dirección Nacional de Geología y Minería, Boletín 126: 106 p. Buenos Aires. 